\title{
Competitividade internacional e tecnologia: uma análise da estrutura das exportações brasileiras ${ }^{1}$
}

\author{
Wellington Pereira ${ }^{2}$ \\ Gabriel Porcile 3 \\ João Furtado ${ }^{4}$
}

\begin{abstract}
Resumo
Neste trabalho, utiliza-se o comércio internacional como uma lente para captar a intensidade tecnológica da estrutura produtiva brasileira. Considera-se que produtos com maior conteúdo tecnológico vistos pelo lado das exportações indicam melhor qualificação da indústria local, contribuindo para uma inserção mais dinâmica nas relações de trocas internacionais. Há alguns indicadores sugeridos para avaliar a evolução da intensidade tecnológica do comércio brasileiro, inclusive a destinação das exportações e uma comparação com a estrutura comercial da Organização para a Cooperação e de Desenvolvimento Econômico (OCDE). Discute-se, dessa forma, em que medida a mudança estrutural no Brasil tem favorecido os setores dinâmicos na tecnologia e comércio. Finalmente, uma matriz de dinamismo comercial é sugerida, combinando indicadores de intensidade tecnológica com o índice de vantagem comparativa revelada.
\end{abstract}

Palavras-chave: Comércio exterior; Tecnologia; Estrutura produtiva.

\begin{abstract}
International competitiveness and technology: an analysis of the structure of Brazilian exports

In this work, international trade is used as a specific vantage point to analyze the technological intensity of Brazil's productive structure. Exports with a higher technological intensity indicate greater local technological capabilities, this leading to a more dynamic international insertion regarding terms of trade. Several indicators are used to measure this intensity, among which are the destination of Brazilian exports and a comparison of Brazilian and OECD exports. These are used to assess the extent to which structural change in Brazil has favored sectors in which technical change and demand growth are higher. Lastly, a matrix of trade dynamism is constructed, crossing the indicators of technological intensity with the index of revealed comparative advantage.
\end{abstract}

Keywords: Foreign trade; Technology; Productive structure.

JEL F14, F41, L60.

\section{Introdução}

Existe um consenso crescente no sentido de que o progresso técnico é uma dimensão chave do desempenho dos países na economia internacional, tanto do

(1) Trabalho recebido em 10 de dezembro de 2007 e aprovado em 13 de junho de 2010.

(2) Professor do Departamento de Economia da Universidade Federal do Paraná (UFPR), Curitiba, PR, Brasil. E-mail: wdspereira@yahoo.com.br.

(3) Professor do Departamento de Economia da UFPR e Pesquisador da Cepal (Comissão Econômica para a América Latina e o Caribe), Curitiba, PR, Brasil. E-mail: porcile@ufpr.br.

(4) Professor da Escola Politécnica da USP (Universidade de São Paulo), São Paulo, SP, Brasil. E-mail: joao1960@gmail.com.

Economia e Sociedade, Campinas, v. 20, n. 3 (43), p. 501-531, dez. 2011. 
ponto de vista do crescimento econômico como do comportamento exportador. Observar com atenção o perfil do comércio internacional do Brasil possibilita aprender muito acerca das mudanças sofridas pela estrutura econômica brasileira e sobre as implicações dessas transformações para o desenvolvimento. Em particular, alterações na estrutura das exportações na direção dos setores mais intensivos em tecnologia e de maior dinamismo no comércio internacional podem gerar taxas mais elevadas de crescimento no longo prazo 5 .

Mais especificamente, o crescimento de longo prazo exige que os países mudem sua estrutura na direção de setores com dinamismo keynesiano (segmentos com maior elasticidade-renda da demanda) e dinamismo schumpeteriano (ramos da atividade econômica em que se verifica maior progresso técnico e maiores ganhos de produtividade). A literatura pertinente sugere que a especialização em setores com esse tipo de dinamismo permite melhorar a inserção internacional e evitar desequilíbrios externos, possibilitando, assim, taxas de crescimento da economia mais elevadas, sustentáveis do ponto de vista do balanço de pagamentos $^{6}$.

Sabe-se que as transformações ocorridas na economia brasileira ao longo das últimas duas décadas afetaram o desempenho competitivo industrial e a pauta de exportações e importações ${ }^{7}$. Este artigo tem como objetivo definir uma matriz de competitividade, agregada e por categorias tecnológicas, para as exportações brasileiras. Diversos trabalhos que analisaram comércio internacional já caminharam em direção similar. A pesquisa aqui apresentada inspira-se na contribuição da Comissão Econômica para América Latina e Caribe (Cepal) ${ }^{8}$, combinando indicadores de intensidade tecnológica e dinamismo da demanda com índices de Vantagem Comparativa Revelada (VCR), para visualizar-se o padrão de especialização.

O artigo está organizado em três seções, além da introdução e conclusões. Na primeira seção, discutem-se os principais indicadores usados no trabalho. Em particular, propõe-se um método que permite captar o dinamismo pelo lado tecnológico (eficiência schumpeteriana) e da demanda internacional (eficiência

(5) Fagerberg (1988a,1988b); Dosi, Pavitt e Soete (1990); Amable e Verspagen (1995); Freeman (2004) e Andersson e Ejermo (2006).

(6) Ao tratar de melhores maneiras de lidar com a mensuração do conteúdo tecnológico, Hausmann, Rodrik e Hwang (2005) acreditam, tal como Lall, Weiss e Zhang (2005), que é necessário o uso da renda per capita dos países como forma de minimizar (ponderar) possíveis desvios no processo de análise. Nesse sentido, a hipótese é de que as exportações tendem a ser mais sofisticadas quanto maior for a renda média do país em questão. A "sofisticação" requer somente informações acerca das exportações de cada produto e da renda per capita dos países exportadores. No entanto, além da dificuldade de obtenção de dados compatíveis (períodos e abrangências) para os diversos países no que se refere à renda, tem-se, ainda, o problema relativo à possível oscilação do "nível de sofisticação" a que um determinado produto pode pertencer.

(7) Castro (1996); Coutinho (1997); Barros e Goldenstein (1997); Ferraz, Kupfer e Haguenauer (1997); Laplane e Sarti (1997); Bielschowsky (1998); Moreira (1999); Negri e Freitas (2004) e Negri (2005).

(8) Para maiores detalhes sobre a construção da metodologia utilizada pela Cepal, Cf. Mandeng (1991). 
keynesiana) a partir da origem e destino das exportações. Trata-se do Índice de Retenção que capta aqueles setores em que a produção e o comércio intraOCDE são mais acentuados. Esse indicador (que capta dimensões tecnológicas e de demanda) é utilizado com a tipologia de Lall (2000) sobre intensidade tecnológica dos setores. Na segunda seção, tais indicadores são combinados com o VCR para produzirem uma matriz de dinamismo do comércio internacional do Brasil. Procura-se identificar o peso das exportações dinâmicas no conjunto das exportações brasileiras e mostrar sua evolução no tempo. Os resultados obtidos com a matriz são apresentados e discutidos na terceira seção.

\section{Dinamismo do comércio internacional brasileiro: alguns indicadores e tendências}

Cada vez com mais frequência, o destino das exportações é usado como critério de qualidade do padrão de exportação ${ }^{9}$. Quando as exportações vão para países desenvolvidos, assume-se que mostram níveis de qualidade e diferenciação mais altos que as exportadas para economias em desenvolvimento. Neste artigo, supõe-se que o produto exportado no interior da OCDE tem tais atributos e, por sua vez, está associado a um maior dinamismo tecnológico e de demanda. Assim, aqueles setores em que o comércio intraOCDE é mais elevado tendem a ser mais dinâmicos em ambos os sentidos (Pereira, 2007).

Os países da OCDE comercializaram 254 grupos de produtos a três dígitos da Standard International Trade Classification - Rev. 3 (SITC) em 2001 (período com estatísticas mais desagregadas e disponíveis, compatíveis com os outros dados utilizados $)^{10}$. O primeiro passo foi estabelecer um critério de cisão entre os conjuntos de produtos de forma a separá-los hierarquicamente conforme a intensidade de sua inserção do ponto de vista do comércio intraOCDE. Calculouse um índice que pudesse dar a idéia do grau de retenção para cada grupo de produtos (SITC 3), ou seja, quanto das exportações da OCDE irá aos países da OCDE em relação às importações totais desse bloco de países:

$$
\frac{X_{i O O}}{M_{i O M}}=\text { Índice de Retenção }
$$

a. $\mathrm{X}_{\mathrm{iOO}}=$ indica as exportações totais do grupo de produtos i da OCDE enviadas para o interior da OCDE.

b. $\mathrm{M}_{\mathrm{iOM}}=$ indica as importações totais do grupo de produtos $\mathrm{i}$ da OCDE originadas de todos os lugares do mundo.

(9) Todas as publicações especializadas em Indicadores de C\&T\&I tem dirigido atenção a este ponto. Veja, por exemplo, os Indicadores de C\&T\&I da Fapesp e as publicações da OCDE e Unctad que discutem a evolução e o perfil do comércio internacional.

(10) Utilizou-se a base de dados Personal Computer Trade Analysis System (PC-TAS) comercializada pela Intracen que tabula informações sobre comércio internacional derivadas da base Comtrade da Organização das Nações Unidas. 
O índice varia entre 0 e 1 , assim, quando ele for 1 , significa dizer que os países da OCDE produzem e consomem a totalidade de bens desse setor. Caso o indicador seja zero, pode-se dizer que todos os produtos consumidos pela OCDE são produzidos externamente ao grupo de países.

O ponto fundamental é não se utilizar, isoladamente, um simples indicador ou uma taxa relativa de crescimento das importações mundiais como proxy da demanda internacional, porque o interesse é definir, ao mesmo tempo, os grupos de produtos que se destacam pela incorporação tecnológica. Considera-se que o Índice de Retenção capta ambos os efeitos, pois trata do comércio dos países que estão na fronteira tecnológica. A Tabela 1 mostra a distribuição dos 254 grupos de produtos comercializados pela OCDE conforme seu Índice de Retenção para o ano de 2001. Vê-se que 150 conjuntos de produtos estão acima da média, isto é, de 0,63 ou $63 \%$, enquanto somente 104 grupos estão abaixo. Os produtos classificamse conforme o posicionamento, ou seja, acima ou abaixo da média do Índice de Retenção (ver Tabela 1) ${ }^{11}$.

Tabela 1

Quantidade de categorias (SITC 3), exportações e importações da OCDE por categorias tecnológicas, 2001

\begin{tabular}{l|c|c|c|c|c|c}
\hline & $\begin{array}{c}\text { Quantidade } \\
\text { de } \\
\text { categorias }\end{array}$ & $\begin{array}{c}\text { Importações } \\
\text { (US\$ } \\
\text { bilhões) }\end{array}$ & $\begin{array}{c}\text { Participação } \\
\text { Relativa (\%) }\end{array}$ & $\begin{array}{c}\text { Exportações } \\
\text { (US\$ } \\
\text { bilhões) }\end{array}$ & $\begin{array}{c}\text { Participação } \\
\text { Relativa } \\
\text { (\%) }\end{array}$ \\
\cline { 2 - 6 } & \multicolumn{5}{|c|}{ Produtos que estão acima da média } \\
\hline Baseados em Recursos & 54 & 508 & 10,3 & 384 & 12,3 \\
\hline Baixa Tecnologia & 26 & 472 & 9,6 & 353 & 11,3 \\
\hline Média Tecnologia & 57 & 1.429 & 29,0 & 1.118 & 35,8 \\
\hline Alta Tecnologia & 13 & 509 & 10,3 & 368 & 11,8 \\
\hline Total acima da média & 150 & 2.918 & 59,2 & 2.224 & 71,3 \\
\hline \multicolumn{7}{|c|}{ Produtos que estão abaixo da média } \\
\hline Baseados em Recursos & 63 & 924 & 18,8 & 375 & 12,0 \\
\hline Baixa Tecnologia & 24 & 509 & 10,3 & 214 & 6,9 \\
\hline Média Tecnologia & 12 & 127 & 2,6 & 56 & 1,8 \\
\hline Alta Tecnologia & 5 & 449 & 9,1 & 252 & 8,1 \\
\hline Total abaixo da média & 104 & 2.010 & 40,8 & 897 & 28,7 \\
\hline Total & 254 & 4.927 & 100 & 3.121 & 100 \\
\hline Fonte: PC-TAS ITC/UNSD. Elaboração própria.
\end{tabular}

Feita essa distinção entre os itens acima e abaixo da média do Índice de Retenção, todos os fluxos comerciais da OCDE foram discriminados de forma que fosse possível ter-se uma primeira impressão da circunstância, das exportações e importações por categorias tecnológicas no ano de 2001, para o qual os índices foram calculados.

(11) A classificação dos produtos por nível tecnológico segue a metodologia aplicada em Lall (2000). No anexo, constam maiores detalhes referentes a cada grupo tecnológico. 
A primeira informação que se obtém é que os produtos acima da média do índice responderam pela maior parcela dos fluxos de exportação e importação com destaque para a categoria de média tecnologia. Ademais, verifica-se que produtos abaixo da média do Índice de Retenção são, em grande medida, baseados em recursos. Esse resultado tende a confirmar a ideia de que a estrutura do comércio intraOCDE é uma proxy do dinamismo tecnológico dos setores. O passo posterior nos procedimentos adotados foi encontrar, entre os grupos de produtos situados acima ou abaixo da média no Índice de Retenção, os que tiveram crescimento positivo das importações entre 1997 e 2001 da OCDE (ver Tabelas 2 e 3). Usar aqueles produtos com crescimento positivo é uma forma de garantir que os bens com dinamismo de demanda sejam inclusos na amostra.

Tabela 2

Importações dos grupos de produtos que estiveram acima da média do Índice de Retenção (OCDE) e apresentaram taxa de crescimento (\%) positiva, 1997 e 2001

\begin{tabular}{l|c|c|c|c|c|c}
\hline & $\begin{array}{c}\text { Quantidade } \\
\text { de grupos }\end{array}$ & $\begin{array}{c}\text { Importações } \\
1997 \\
\text { (US\$ bi) }\end{array}$ & $\begin{array}{c}\text { Importações } \\
2001 \\
\text { (US\$ bi) }\end{array}$ & $\begin{array}{c}\text { Participação } \\
\text { Rel. (\%) } \\
1997\end{array}$ & $\begin{array}{c}\text { Participação } \\
\text { Rel. (\%) } \\
2001\end{array}$ & $\begin{array}{c}\text { Taxa de } \\
\text { crescimento } \\
1997-2001\end{array}$ \\
\hline $\begin{array}{c}\text { Baseados em } \\
\text { Recursos }\end{array}$ & 29 & 351 & 382 & 16,7 & 15,0 & 1,7 \\
\hline $\begin{array}{c}\text { Baixa } \\
\text { Tecnologia }\end{array}$ & 17 & 334 & 407 & 15,9 & 16,0 & 4,0 \\
\hline $\begin{array}{c}\text { Média } \\
\text { Tecnologia }\end{array}$ & 39 & 1.066 & 1.259 & 50,7 & 49,4 & 3,4 \\
\hline $\begin{array}{c}\text { Alta } \\
\text { Tecnologia }\end{array}$ & 12 & 351 & 499 & 16,7 & 19,6 & 7,3 \\
\hline Total & 97 & 2.101 & 2.546 & 100 & 100 & 3,9 \\
\hline
\end{tabular}

Fonte: PC-TAS ITC/UNSD. Elaboração própria.

Tabela 3

Importações dos grupos de produtos que estiveram abaixo da média do Índice de Retenção (OCDE) e apresentaram taxa de crescimento (\%) positiva, 1997 e 2001

\begin{tabular}{l|c|c|c|c|c|c}
\hline & $\begin{array}{c}\text { Quantidade } \\
\text { de grupos }\end{array}$ & $\begin{array}{c}\text { Importações } \\
1997 \\
\text { (US\$ bi) }\end{array}$ & $\begin{array}{c}\text { Importações } \\
2001 \\
\text { (US\$ bi) }\end{array}$ & $\begin{array}{c}\text { Participação } \\
\text { Rel. (\%) } \\
1997\end{array}$ & $\begin{array}{c}\text { Participação } \\
\text { Rel. (\%) } \\
2001\end{array}$ & $\begin{array}{c}\text { Taxa de } \\
\text { crescimento } \\
1997-2001\end{array}$ \\
\hline $\begin{array}{c}\text { Baseados em } \\
\text { Recursos }\end{array}$ & 24 & 534 & 692 & 38,9 & 41,7 & 5,3 \\
\hline $\begin{array}{c}\text { Baixa } \\
\text { Tecnologia }\end{array}$ & 17 & 368 & 433 & 26,8 & 26,1 & 3,3 \\
\hline $\begin{array}{c}\text { Média } \\
\text { Tecnologia }\end{array}$ & 6 & 71 & 83 & 5,2 & 5,0 & 3,3 \\
\hline $\begin{array}{c}\text { Alta } \\
\text { Tecnologia }\end{array}$ & 5 & 400 & 449 & 29,1 & 27,1 & 2,3 \\
\hline Total & 52 & 1.373 & 1.656 & 100 & 100 & 3,8 \\
\hline
\end{tabular}

Fonte: PC-TAS ITC/UNSD. Elaboração própria. 
As Tabelas 2 e 3 mostram que, depois do filtro dos itens com crescimento positivo do comércio entre 1997 e 2001, sobraram 97 categorias acima da média do Índice de Retenção e 52 abaixo da média. O crescimento médio anual em ambos os casos foi bastante próximo, diferindo mais fortemente no que diz respeito aos montantes de importação. A diferença entre as importações de produtos acima e abaixo da média em 2001 foi de US\$ 890 bilhões, indicando a "maior importância" das categorias com Índices de Retenção superiores à média. Além disso, no último caso, a categoria de alta tecnologia foi a que deteve a maior taxa de crescimento entre 1997 e 2001 (7,3\%), frente aos produtos básicos os quais ocuparam a mesma posição de maior taxa $(5,3 \%)$ em meio aos grupos abaixo da média.

Definidas todas as categorias a partir da proxy adotada (Índice de Retenção e da taxa de crescimento das importações da OCDE), torna-se possível avançar no exame da estrutura das exportações brasileiras. Com a lista e seleção das importações com crescimento positivo entre 1997 e 2001 (ou seja, 97 casos acima e 52 abaixo da média do índice), o passo conseguinte foi encontrar o desempenho desses grupos nas exportações do Brasil.

Os citados grupos de produtos foram alocados entre 10 categorias tecnológicas descritas em Lall (2000). Elas podem ser visualizadas na Figura 1 que possibilita verificar como se comportam as vendas externas do Brasil por nível tecnológico nos anos de 1995, 2000 e 2005. As categorias de produtos primários (PP) e BR formam o grupo Baseados em Recursos, as BT referem-se à Baixa Tecnologia, MT, à Média Tecnologia e AT, à Alta Tecnologia.

Os produtos que constam nessa análise são os mesmos selecionados nas transações comerciais da OCDE, vistos anteriormente. Com tal procedimento, compara-se a estrutura do comércio do Brasil com aquela do bloco de países economicamente mais importantes do mundo, combinando o Índice de Retenção com a tipologia de Lall (2000) sobre intensidade tecnológica ${ }^{12}$.

A figura que apresenta as exportações dos grupos de produtos acima da média de retenção mostra que, entre 1995 e 2005, houve um avanço significativo para a maioria das categorias tecnológicas - as exceções foram PP, BR2, BT1 e AT2. O primeiro gráfico mostra que, em meio às categorias acima da média de retenção e com crescimento positivo, concentravam-se segmentos mais intensivos em tecnologia. É possível verificar que o Brasil apresentou crescimento destacado nas exportações das três categorias de média tecnologia e, na primeira, de alta

(12) Apesar de a China ter ganhado proeminência no cenário econômico internacional recentemente devido ao crescimento acelerado de seu produto, optou-se por mantê-la fora dessa análise, pois seu padrão de industrialização difere em relação àquele dos países da OCDE. Além disso, a China merece uma análise individualizada dada a complexidade de suas relações econômicas. 
tecnologia (eletrônicos/elétricos), acompanhando a tendência do comportamento das transações comerciais da OCDE. O segundo gráfico (b) mostra que as categorias de produtos abaixo da média detêm uma concentração nos segmentos menos intensivos em tecnologia (PP, BR1, BR2, BT1 e BT2), o que se reflete nas exportações do Brasil desses itens.

Figura 1

Exportações brasileiras (US\$ bi) por categorias tecnológicas (acima e abaixo da média do Índice de Retenção da OCDE) - Brasil, 1995, 2000 e 2005*

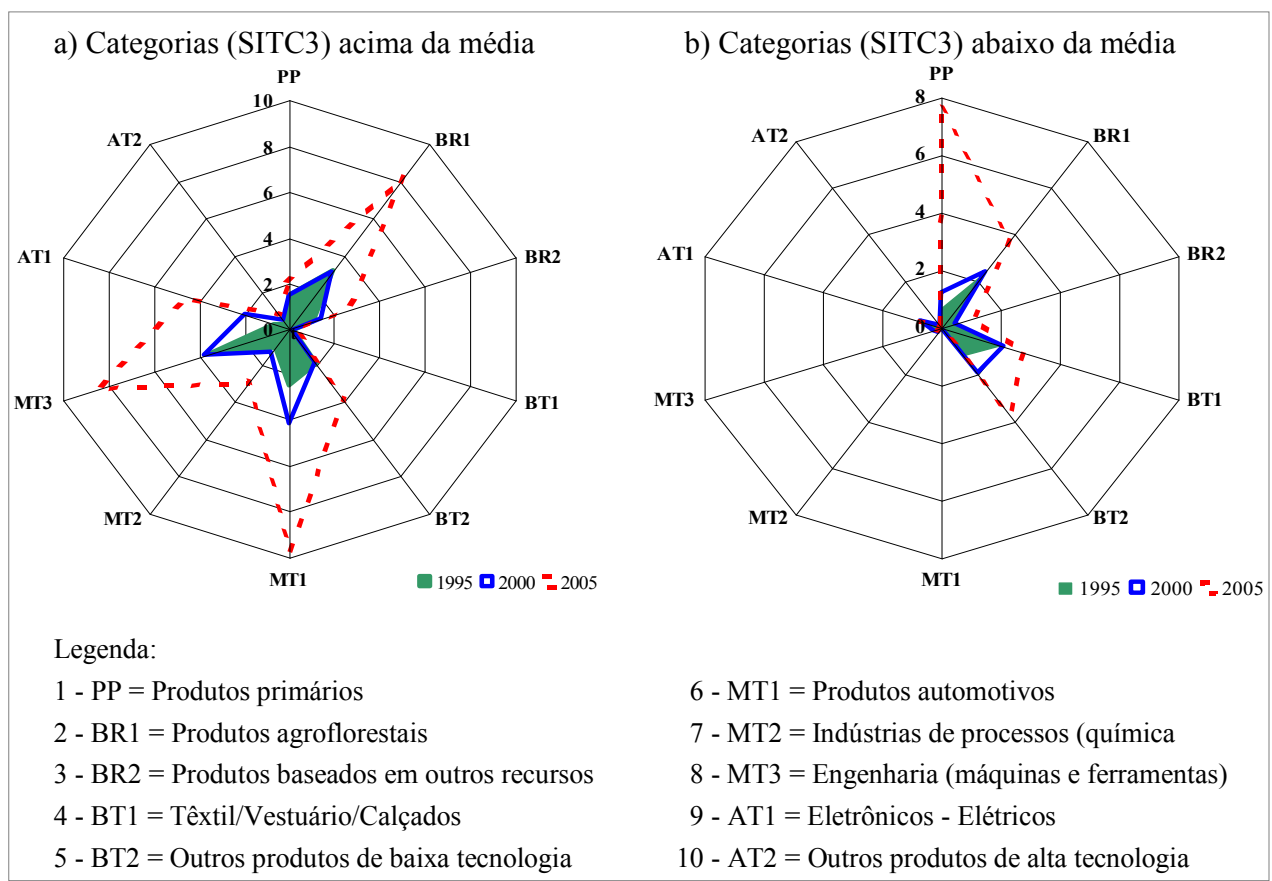

* No anexo, constam maiores detalhes sobre a atribuição de cada categoria tecnológica.

Fonte: Secex. Elaboração própria.

As taxas de crescimento para cada grupo de produtos (acima e abaixo da média) mostram que, em todos os períodos selecionados, as exportações totais cresceram a taxas positivas, mas com diferenças importantes. Uma primeira constatação interessante refere-se ao comportamento das categorias (no grupo acima da média do Índice de Retenção) Produtos Primários, BR1, BT1 e BT2 que apresentaram crescimento negativo entre 1995-2000 - período marcado pela sobrevalorização cambial. Mesmo sendo produtos em que o país detém certa vantagem competitiva, as exportações desses itens tiveram desempenho desfavorável. Ao contrário, as exportações dos produtos das categorias mais intensivas em tecnologia tiveram taxas de crescimento significativas. 
Tabela 4

Taxas de crescimento anualizadas (\%) das Exportações Brasileiras por categorias tecnológicas (acima e abaixo da média do Indice de Retenção OCDE)

\begin{tabular}{l|r|r|r|r|r|r|r|r}
\hline & \multicolumn{4}{|c|}{ Categorias acima da média } & \multicolumn{4}{c}{ Categorias abaixo da média } \\
\cline { 2 - 10 } & $1990-95$ & $1995-00$ & $2000-05$ & $1990-05$ & $1990-95$ & $1995-00$ & $2000-05$ & $1990-05$ \\
\hline 1. Produtos Primários & 6,0 & $-0,1$ & 5,1 & 4,1 & $-5,8$ & 11,7 & 35,7 & 14,3 \\
\hline 2. BR1 - Agroflorestal & 14,2 & $-0,1$ & 17,6 & 11,6 & 15,4 & 1,7 & 7,5 & 9,1 \\
\hline 3. BR2 - Outros & 9,3 & 3,9 & 11,2 & 9,1 & 10,2 & 1,4 & 15,7 & 10,1 \\
\hline 4. BT1 -Têxtil/Vestuário/Calçados & 13,6 & $-3,6$ & 9,0 & 6,9 & 3,8 & 0,9 & 4,7 & 3,5 \\
\hline 5. BT2 - Outros & 6,4 & $-1,0$ & 13,5 & 7,0 & 11,5 & 8,2 & 11,5 & 11,8 \\
\hline 6. MT1 - Automotivos & 8,9 & 8,8 & 15,5 & 12,5 & - & - & - & - \\
\hline 7. MT2 - Processos & 9,8 & 4,1 & 14,9 & 10,8 & 10,3 & $-2,1$ & 15,7 & 8,7 \\
\hline 8. MT3 - Engenharia & 7,8 & 1,2 & 14,4 & 8,7 & 1,7 & $-5,4$ & $-18,8$ & $-8,8$ \\
\hline 9. AT1 - Eletrônicos/Elétricos & 8,8 & 21,5 & 14,2 & 16,7 & 12,0 & 10,9 & 0,5 & 8,7 \\
\hline 10. AT2 - Outros & 9,5 & 9,7 & 9,7 & 10,9 & 4,7 & 14,8 & 4,4 & 8,9 \\
\hline Total & 9,0 & 3,7 & 14,2 & 10,1 & 7,0 & 4,0 & 13,7 & 9,2 \\
\hline
\end{tabular}

Fonte: Secex. Elaboração própria.

Tabela 5

Valores médios das Exportações Brasileiras por categorias tecnológicas (acima e abaixo da média do Índice de Retenção OCDE)

\begin{tabular}{l|r|r|r|r|r|r|r|r}
\hline & \multicolumn{4}{|c|}{ Categorias acima da média } & \multicolumn{4}{c}{ Categorias abaixo da média } \\
\cline { 2 - 9 } & 1990 & 1995 & 2000 & 2005 & 1990 & 1995 & 2000 & 2005 \\
\hline 1.Produtos Primários & 1,44 & 1,43 & 1,49 & 1,89 & 0,13 & 0,20 & 0,27 & 0,33 \\
\hline 2.BR1 - Agroflorestal & 1,23 & 1,36 & 1,11 & 1,24 & 0,41 & 0,40 & 0,54 & 0,44 \\
\hline 3.BR2 - Outros & 0,55 & 0,55 & 0,63 & 1,00 & 1,11 & 0,82 & 0,40 & 0,39 \\
\hline 4.BT1 -Têxtil/Vestuário/Calçados & 1,26 & 1,74 & 1,67 & 2,49 & 15,65 & 14,64 & 11,94 & 12,54 \\
\hline 5.BT2 - Outros & 0,59 & 0,81 & 0,81 & 0,92 & 0,31 & 0,35 & 0,39 & 0,62 \\
\hline 6.MT1 - Automotivos & 5,87 & 4,99 & 5,20 & 5,68 & - & - & - & - \\
\hline 7.MT2 - Processos & 1,03 & 1,17 & 1,10 & 1,56 & 0,35 & 0,41 & 0,44 & 0,43 \\
\hline 8.MT3 - Engenharia & 5,26 & 5,80 & 5,03 & 5,73 & 73,31 & 71,44 & 55,77 & 26,98 \\
\hline 9.AT1 - Eletrônicos/Elétricos & 8,17 & 6,03 & 12,23 & 12,96 & 36,24 & 15,42 & 10,76 & 9,95 \\
\hline 10.AT2 - Outros & 36,11 & 24,64 & 18,50 & 21,56 & 0,57 & 0,55 & 0,95 & 1,00 \\
\hline Total & 1,40 & 1,59 & 1,74 & 2,16 & 0,41 & 0,56 & 0,59 & 0,49 \\
\hline
\end{tabular}

Fonte: Secex. Elaboração própria. 
Nas categorias com Índice de Retenção abaixo da média, as taxas de crescimento das exportações do Brasil entre 2000 e 2005 foram elevadas em alguns dos segmentos básicos e de baixa tecnologia (produtos primários, BT2 e $\mathrm{BR} 2$ ). Entre os casos de média e alta tecnologia (com exceção da categoria processos), verificou-se que o desempenho não foi tão favorável.

Fato curioso referiu-se à alta taxa de crescimento (relativamente às demais) das exportações da categoria Produtos Primários (dentre os casos abaixo da média de retenção), contribuindo para reforçar o argumento de ter sido um dos segmentos que resistiu melhor ao período de sobrevalorização (1995-2000).

O exame dos valores médios ${ }^{13}$ das exportações brasileiras, calculados para os grupos de produtos alocados entre categorias acima e abaixo da média de retenção, não traz surpresas. Fica clara a divisão das categorias em dois grupos. No primeiro deles (acima da média), os valores médios dos segmentos menos intensivos em tecnologia são maiores que os apresentados para o segundo caso (abaixo da média). As exceções destacadas são as categorias Engenharia, Elétrico/Eletrônicos e Têxtil/Vestuário/Calçados. Ambas apresentaram valores médios bastante superiores para os produtos situados abaixo da média do Índice de Retenção. Esse pode ser um fator positivo, primeiro, por indicar exportações que têm possibilidades de inserção externa mais competitiva e, segundo, por seus valores médios mais elevados serem indicativos da posse de maior valor agregado.

Obtidas as primeiras impressões de como se têm comportado os grupos de produtos pré-selecionados no âmbito do comércio internacional brasileiro, o passo seguinte tratou da construção das matrizes de dinamismo para as exportações totais e por categorias tecnológicas do Brasil.

\section{Matriz de dinamismo das exportações brasileiras}

A demarcação e hierarquização dos produtos e suas respectivas categorias como mais intensivos em tecnologia (casos que crescem positivamente acima e abaixo da média do Índice de Retenção, calculado em relação às transações comerciais da OCDE e aplicados à pauta brasileira) foi o procedimento inicial para o avanço no exame do estado de dinamismo das exportações do Brasil. Seu desdobramento exige uma análise ampla para cada categoria tecnológica. Com base nessa consideração, foram definidas matrizes de dinamismo para as exportações brasileiras totais e desagregadas por categorias tecnológicas, inspirando-se nos desenvolvimentos similares já aplicados, por exemplo, pela Comissão Econômica para a América Latina e o Caribe (Cepal) na análise da competitividade dos países no que diz respeito ao comércio internacional ${ }^{14}$. Os

(13) Adota-se a hipótese utilizada em numerosos estudos, segundo a qual produtos com maior conteúdo tecnológico possuem valor médio (cociente do valor em US\$ do produto em relação a seu peso em quilogramas) mais elevado - atestando uma proxy para a densidade industrial e tecnológica dos bens comercializados.

(14) Para maiores detalhes sobre a construção da metodologia utilizada pela Cepal, cf. Mandeng (1991). 
dados da Secretaria de Comércio Exterior (SECEX) referentes às exportações brasileiras foram tabulados sob a ótica da classificação internacional padrão de mercadorias adotada na apresentação de estatísticas comerciais - a SITC Rev.3 a três dígitos.

Além da alocação dos grupos de produtos SITC Rev.3 a três dígitos entre os casos acima e abaixo da média de retenção, a construção das matrizes de dinamismo necessitava de outro indicador que complementasse a análise, focando na especialização. Assim, a opção escolhida foi o índice de Vantagem Comparativa Revelada (VCR), calculado para cada um dos 149 grupos de produtos já selecionados anteriormente ( 97 acima da média e 52 abaixo da média do Índice de Retenção calculado para os países da OCDE e ambos com crescimento positivo das importações da OCDE entre 1997-2001). O índice de vantagem comparativa revelada foi desenvolvido por Bela Balassa em $1965^{15} \mathrm{com}$ o propósito de verificar a vantagem comparativa entre os países a partir de seus fluxos de comércio ${ }^{16}$. A suposição adotada é que, ao ser o índice de VCR superior à unidade, o país detém vantagem comparativa no produto.

O passo posterior foi a construção da matriz de dinamismo. Os quatro quadrantes foram definidos em função dos conjuntos de produtos acima e abaixo da média de retenção em relação às transações comerciais da OCDE (todos com crescimento positivo das importações entre 1997 e 2001) e entre aqueles que apresentaram índice de VCR acima e abaixo da unidade. Um modelo explicativo descrevendo cada quadrante da matriz é apresentado de forma a facilitar o entendimento e a alocação de todos os grupos de produtos.

O índice de VCR é utilizado sob a perspectiva de contribuir para a compreensão do dinamismo tecnológico do país que se reflete no padrão de especialização.

Assim, após os desenvolvimentos cabíveis no que se refere aos procedimentos metodológicos, foram calculados os índices de VCR das

(15) Ver Balassa (1965).

(16) O suposto por trás da construção do índice é que a eficiência produtiva de um país pode ser observada por meio das transações comerciais. Na época de seu desenvolvimento, o índice de VCR ganhou maior respaldo perante a academia por ter sido adotado por diversas instituições, dentre elas o Banco Mundial. A literatura, em geral, sugere que o uso desse indicador, no entanto, deva ser feito com cautela porque seu uso poderá indicar que os fluxos de comércio não estejam sendo afetados por fatores que destorcem o cenário, como subsídios, restrições quantitativas, tarifas etc. Esse, porém, não deixa de ser um problema que afeta todos os indicadores construídos em torno das estatísticas comerciais. O indicador elaborado por Balassa pode ser apresentado da seguinte forma:

$$
V C R=\frac{X_{i j} / X_{n j}}{X_{i t} / X_{n t}}
$$

em que i representa o país e j o setor, $\mathrm{t}$ refere-se ao total da indústria de manufatura e $\mathrm{n}$ ao universo de países (ou ao mundo). 
exportações brasileiras para os 149 grupos de produtos SITC a três dígitos e estes, distribuídos entre os quadrantes, conforme suas características. Inicialmente, apresenta-se a matriz para o caso das exportações totais do Brasil e, em seguida, um exame sucinto é realizado de forma desagregada para cada uma das dez categorias tecnológicas.

Figura 2

Matriz de dinamismo das exportações do Brasil (modelo explicativo)

\begin{tabular}{|c|c|c|}
\hline & $\begin{array}{l}\text { Produtos inferiores à média de retenção } \\
\text { OCDE }\end{array}$ & $\begin{array}{l}\text { Produtos superiores à média de retenção } \\
\text { OCDE }\end{array}$ \\
\hline 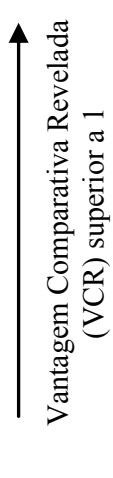 & $\begin{array}{l}\text { O quarto quadrante apresenta o } \\
\text { comportamento de produtos que, apesar } \\
\text { de deterem índice de VCR superior a 1, } \\
\text { estiveram abaixo da média em relação ao } \\
\text { grupo de produtos da OCDE. São, } \\
\text { principalmente, produtos básicos e de } \\
\text { baixa tecnologia que o Brasil destaca-se } \\
\text { em termos de inserção externa. Em } \\
\text { relação à taxonomia da Cepal, tratar-se-ia } \\
\text { de um caso próximo às "estrelas } \\
\text { minguantes". São casos, no entanto, que } \\
\text { merecem atenção por responderem por } \\
\text { especializações significativas. }\end{array}$ & $\begin{array}{l}\text { O primeiro quadrante trata dos produtos } \\
\text { que tiveram índice de especialização ou } \\
\text { VCR superior a } 1 \text { e estiveram acima da } \\
\text { média observada para o conjunto da } \\
\text { OCDE. São produtos que indicam } \\
\text { oportunidades superiores em termos de } \\
\text { dinamismo, por um lado, visto sob a ótica } \\
\text { da demanda internacional, e por outro, } \\
\text { devido à maior "vantagem competitiva" } \\
\text { (ou vantagem) pelo lado da oferta interna. } \\
\text { Numa perspectiva aproximada com a } \\
\text { tipologia da Cepal poderia ser nomeada } \\
\text { como "estrelas nascentes". }\end{array}$ \\
\hline 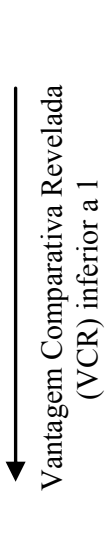 & $\begin{array}{l}\text { O terceiro quadrante é aquele que } \\
\text { representa os produtos em que o grau de } \\
\text { especialização é inferior e estão abaixo da } \\
\text { média do conjunto da OCDE, indicando } \\
\text { uma situação menos positiva em termos } \\
\text { de dinamismo pelo lado demanda e da } \\
\text { oferta. É o caso que se aproxima das } \\
\text { "oportunidades de retirada" da Cepal. Isso } \\
\text { tende a indicar que esforços para } \\
\text { impulsionar as transações comerciais não } \\
\text { seriam tão benéficos. Apesar de uma } \\
\text { participação razoável de itens de alta } \\
\text { tecnologia, os produtos primários e } \\
\text { aqueles de baixa tecnologia responderam } \\
\text { pela maioria. }\end{array}$ & $\begin{array}{l}\text { O segundo quadrante mostra os casos } \\
\text { possuidores de VCR inferiores a } 1 \text {, mas } \\
\text { "dinâmicos" sob a ótica das relações } \\
\text { comerciais da OCDE. Em sua maioria, } \\
\text { são representados por produtos de alta e } \\
\text { média tecnologia. São casos em que o } \\
\text { Brasil detém pouca especialização e, } \\
\text { talvez, eles destoem mais fortemente em } \\
\text { termos das características de inserção } \\
\text { competitiva vista sob a perspectiva dos } \\
\text { maiores conteúdos tecnológicos. É a } \\
\text { aproximação ao caso das "oportunidades } \\
\text { perdidas" da Cepal. }\end{array}$ \\
\hline
\end{tabular}

Notas: a) Vale lembrar que a definição da média do Índice de Retenção foi calculada a partir das transações comerciais realizadas intraOCDE e, somente, aplicada ao comércio brasileiro no que diz respeito ao filtro dos grupos de produtos; b) Os índices de Vantagem Comparativa Revelada (VCR) calculados e apresentados nas análises subseqüentes foram efetuados para as exportações do Brasil.

Em cada quadrante da matriz de dinamismo (ou seja, para todos os grupos de produtos pertinentes ao quadrante), foram calculados os seguintes indicadores para as exportações brasileiras: i) quantidade de categorias; ii) taxa de crescimento anualizada (\%); iii) exportações (em dólares) e participação relativa (\%) sobre o total, por grupos tecnológicos agregados (Produtos Básicos, Baixa Tecnologia, Média Tecnologia e Alta Tecnologia); iv) valores médios; v) saldo comercial. 
Tabela 6

Matriz de dinamismo das exportações brasileiras *

Produtos inferiores à média de retenção OCDE

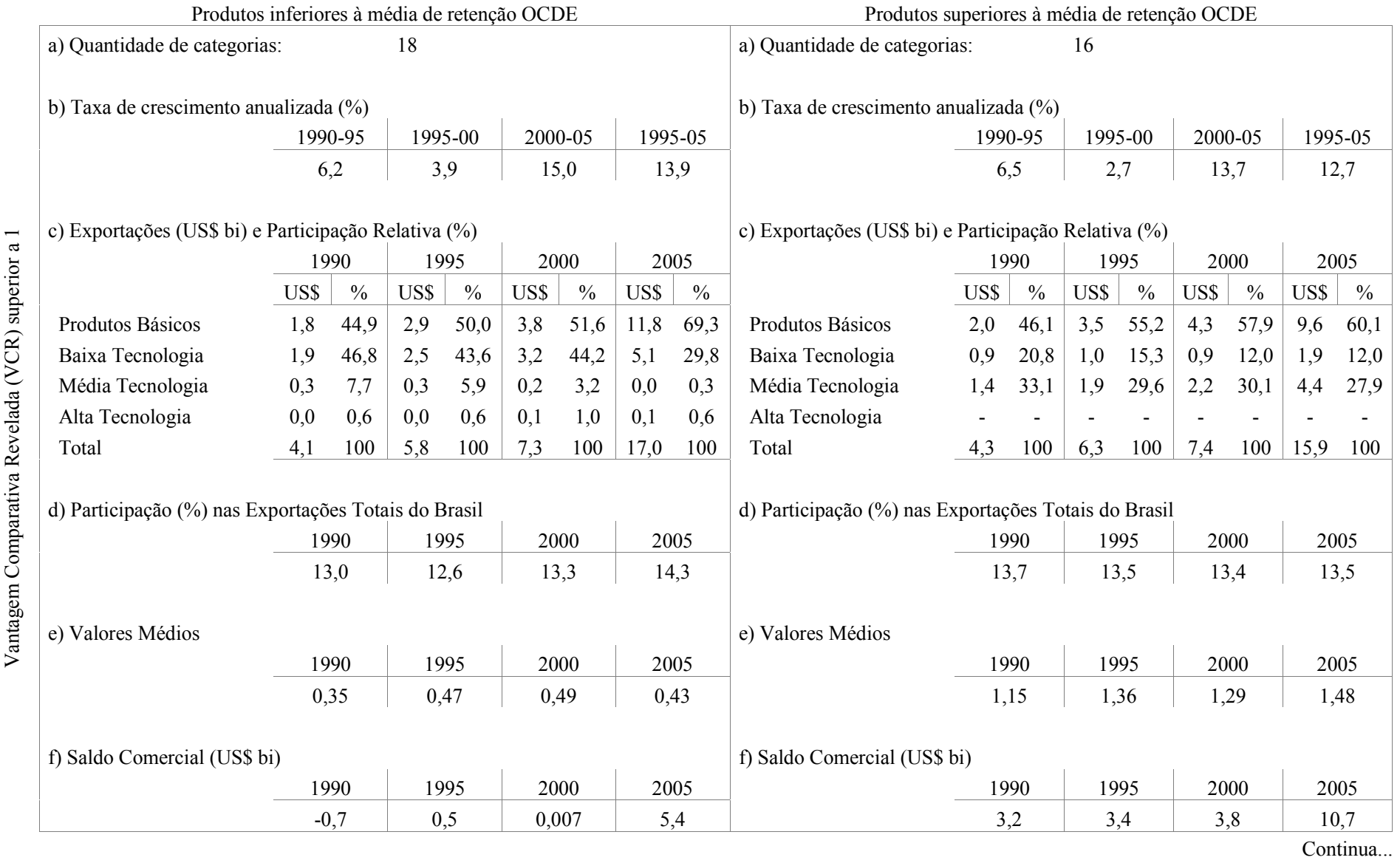


Tabela 6 - Continuação

\begin{tabular}{|c|c|c|c|c|c|c|c|c|c|c|c|c|c|c|c|c|}
\hline \multicolumn{8}{|c|}{ Produtos inferiores à média de retenção $\mathrm{OCDE}$} & \multicolumn{9}{|c|}{ Produtos superiores à média de retenção OCDE } \\
\hline \multicolumn{2}{|c|}{ a) Quantidade de categorias: } & \multicolumn{6}{|l|}{31} & \multirow{2}{*}{\multicolumn{9}{|c|}{$\begin{array}{l}\text { a) Quantidade de categorias: } \\
\text { b) Taxa de crescimento anualizada (\%) }\end{array}$}} \\
\hline \multicolumn{8}{|c|}{ b) Taxa de crescimento anualizada (\%) } & & & & & & & & & \\
\hline & 10,6 & & & 8 & & & & & 11 & 1,0 & \multicolumn{2}{|c|}{4,4} & \multicolumn{2}{|c|}{14,5} & \multicolumn{2}{|c|}{16,6} \\
\hline \multicolumn{8}{|c|}{ c) Exportações (US\$ bi) e Participação Relativa (\%) } & \multicolumn{9}{|c|}{ c) Exportações (US\$ bi) e Participação Relativa (\%) } \\
\hline & 1990 & \multicolumn{2}{|c|}{1995} & \multicolumn{2}{|c|}{2000} & \multicolumn{2}{|c|}{2005} & & \multicolumn{2}{|c|}{1990} & \multicolumn{2}{|c|}{1995} & \multicolumn{2}{|c|}{2000} & \multicolumn{2}{|c|}{2005} \\
\hline & US\$ $\%$ & US\$ & $\%$ & US\$ & $\%$ & US\$ & $\%$ & & US\$ & $\%$ & US\$ & $\%$ & US\$ & $\%$ & US\$ & $\%$ \\
\hline Produtos Básicos & $0,2 \quad 25,3$ & 0,3 & 18,2 & 0,3 & 13,6 & 0,6 & 18,2 & Produtos Básicos & 1,1 & 22,0 & 2,2 & 23,6 & 1,7 & 13,7 & 3,2 & 11,6 \\
\hline Baixa Tecnologia & $0,3 \quad 37,4$ & 0,7 & 42,8 & 0,8 & 40,6 & 1,5 & 45,0 & Baixa Tecnologia & 0,5 & 10,3 & 1,1 & 12,2 & 1,1 & 8,9 & 2,2 & 8,2 \\
\hline Média Tecnologia & $0,1 \quad 13,9$ & 0,2 & 13,8 & 0,2 & 9,8 & 0,5 & 14,0 & Média Tecnologia & 2,9 & 57,4 & 5,1 & 54,9 & 6,9 & 57,3 & 16,7 & 61,3 \\
\hline Alta Tecnologia & $0,2 \quad 23,4$ & 0,4 & 25,2 & 0,7 & 35,9 & 0,7 & 22,8 & Alta Tecnologia & 0,5 & 10,3 & 0,9 & 9,3 & 2,4 & 20,1 & 5,2 & 19,0 \\
\hline Total & $0,8 \quad 100$ & 1,6 & 100 & 2,0 & 100 & 3,3 & 100 & Total & 5,0 & 100 & 9,4 & 100 & 12,1 & 100 & 27,3 & 100 \\
\hline \multicolumn{8}{|c|}{ d) Participação (\%) nas Exportações Totais do Brasil } & \multicolumn{9}{|c|}{ d) Participação (\%) nas Exportações Totais do Brasil } \\
\hline & 1990 & & & 20 & & & & & 19 & 90 & 19 & 95 & 20 & 00 & & 05 \\
\hline & 2,7 & & & 3 & & & & & 16 & 5,0 & 20 & 2 & 22 & 2,0 & & 3,1 \\
\hline e) Valores Médios & & & & & & & & e) Valores Médios & & & & & & & & \\
\hline & 1990 & & & 20 & & & & & 19 & 90 & 19 & 95 & 20 & 00 & & 05 \\
\hline & 2,04 & & & 2 , & & & & & 1 , & 72 & 1 , & 78 & 2, & 21 & & 93 \\
\hline f) Saldo Comercial ( & bi) & & & & & & & f) Saldo Comercial ( & $\$$ bi) & & & & & & & \\
\hline & 1990 & & & 20 & & & & & 19 & 90 & 19 & 95 & 20 & 00 & & 05 \\
\hline & $-2,1$ & & & $-\varepsilon$ & ,5 & & & & -0 &, 8 & -1 & 1,1 & 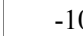 & 0,4 & &, 9 \\
\hline
\end{tabular}

* A lista com a definição (sua respectiva nomenclatura) de cada grupo de produto está no Anexo.

Fonte: Secex. Elaboração própria. 
A seguir, a tipologia apresentada acima que inclui as dimensões tecnológicas e de demanda é utilizada para analisar em que medida a mudança estrutural no Brasil exprime um movimento na direção de setores de maior potencial de crescimento no longo prazo.

\section{Estrutura competitiva das exportações brasileiras}

A seguir, são analisados os componentes dos quadrantes (em sentido horário) da matriz de dinamismo apresentada na seção anterior.

$\rightarrow$ Produtos com vantagem comparativa revelada superior à unidade $e$ possuidores de Índice de Retenção superior à média de retenção (63\%) da OCDE:

Esse foi o quadrante com o menor número de grupos de produtos, mas o que respondeu aos maiores superávits entre 1990 e 2005. Ele trata dos principais casos de maior inserção internacional (competitiva) brasileira, sobretudo devido à grande participação de produtos básicos $(60,1 \%)$ e média tecnologia $(27,9 \%)$ nada foi registrado em relação à alta tecnologia. Isso ocorre porque, de todos os produtos com índice de retenção superior à média da seleção inicial, tiveram VCR inferiores à unidade. O montante exportado em 2005, nesse quadrante situou-se em terceiro lugar entre os outros três. As exportações cresceram menos entre 1995 e 2005 perante outros quadrantes, mas permaneceram com uma taxa de crescimento cujo valor não está distante daqueles vistos para outros produtos. São alguns traços que podem sinalizar para um dinamismo mais fraco dos produtos quando exportados pelo Brasil, diferentemente do que ocorre com os fluxos comerciais dos mesmos itens intraOCDE. Tal resultado tem relação com o fato de que os produtos com valor do índice de retenção superior à média são menos demandados pela OCDE a partir de países fora desse grupo. Apesar de o Brasil não destinar todos os produtos do primeiro quadrante somente à OCDE, é importante registrar o fato, destacando que produtos de alta tecnologia não apareceram no referido filtro. O quadrante mostra que parte dos produtos intraOCDE destaca-se por ter um índice de retenção superior à média e possuir VCR inferior a 1, com atenção aos produtos de alta tecnologia exportados pelo Brasil, compreendidos nesse caso (segundo quadrante no sentido horário). A dúvida que fica é até que ponto as exportações brasileiras dos itens selecionados têm condições efetivas de se inserirem nos mercados nos países da OCDE, por exemplo. Isso poderá ser uma informação importante para o planejamento das vendas para outros países, tal como da competitividade que se pode atingir dada as divisões entre produtos com VCR acima e abaixo da unidade.

$\rightarrow$ Produtos com vantagem comparativa revelada inferior a unidade $e$ possuidores de indice de retenção superior à média de retenção (63\%) da OCDE:

O segundo quadrante é reservado, sobretudo, para as categorias de média e alta tecnologia que, juntas, responderam por mais de $80 \%$ das exportações. A 
metodologia de análise construída no artigo indica que este quadrante tende a não mostrar possibilidades de maiores "ganhos" via inserção externa. Isso porque são produtos cujo comércio intraOCDE é maior e possuem VCR inferior à unidade. As estatísticas, no entanto, mostram que a evolução do montante exportado foi significativa, detendo a maior taxa de crescimento dentre os demais quadrantes entre 1995-2005 (16,6\%). Isso não é desprezível. Seu déficit, porém, foi acentuado entre 1995 e 2000, apresentando valores bem menores em 2005. Os valores médios foram os maiores registrados nos anos mais recentes, reforçando a característica de se tratar de mercadorias mais intensivas em tecnologia. Nota-se que o desempenho brasileiro passou por alterações positivas nesse período, pois o crescimento das exportações, no caso, tem resultado em diminuição do déficit e aumento nas vendas de itens com maiores valores médios. Ademais, registra-se que a participação relativa de tais produtos nas exportações totais do Brasil foi a maior entre todos os demais quadrantes e atingiu $23 \%$ em 2005 - o que indica um sinal positivo no que se refere ao tipo de mercadoria vendida ao exterior, sobretudo pela prevalência dos níveis de média e alta tecnologia.

$\rightarrow$ Produtos com vantagem comparativa revelada inferior à unidade $e$ possuidores de índice de retenção inferior à média de retenção (63\%) da OCDE

No que se refere ao terceiro quadrante (segundo em número de categorias de produtos e quarto em montante exportado), nota-se a supremacia dos grupos de produtos primários e de baixa tecnologia. Esse é o caso de contraponto ao primeiro quadrante, pois possibilita distinguir as mercadorias que teriam (ou vêm tendo) maiores "oportunidades" devido ao caráter tecnológico (produtos no grupo acima da média de retenção da OCDE) em relação aos com VCR inferior a 1, sem receberem sinalizações positivas do mercado externo (terceiro quadrante). Tal constatação ganha mais força ao se observar que o déficit comercial cresceu ao longo do tempo (sai de US\$ 2,1 bilhões em 1990 para atingir US\$ 11,1 bilhões em 2005), refletindo a falta de competitividade nos principais itens (destacadamente, produtos básicos e baixa tecnologia) os quais constituem este caso - mesmo sendo grupos tecnológicos que detêm parcelas significativas das exportações brasileiras e de competitividade externa (commodities agrícolas e minerais). $\mathrm{O}$ fator menos agravante quanto ao quadrante citado é que a participação relativa dos produtos pertencentes a ele (devido ao filtro realizado) em relação ao total das exportações do Brasil é pequena, não ultrapassando $4 \%$.

$\rightarrow$ Produtos com vantagem comparativa revelada superior à unidade $e$ possuidores de indice de retenção inferior à média de retenção (63\%) da OCDE

O exame dos resultados para o quarto quadrante mostra que os valores médios (indicadores - proxies - de maior dinamismo tecnológico ou mesmo, de valor agregado) foram inferiores em relação ao primeiro quadrante, os quais são 
similares quanto às categorias tecnológicas preponderantes. Isso é reforçado pela distribuição das vendas entre grupos tecnológicos a qual reforça o peso de itens referentes a produtos básicos e de baixa tecnologia que, juntos, responderam por mais de 99\% dos fluxos em 2005 (e na mesma proporção nos anos prévios). O quarto quadrante representa, de forma característica, a situação da maior parcela das exportações brasileiras, ao menos daquelas que conseguiram angariar maiores parcelas (ou mesmo, competitividade) do mercado externo. Ademais, ocupou o segundo lugar no que tange ao montante exportado e vem obtendo superávits crescentes ao longo dos anos - saiu de um déficit de US\$ 700 milhões em 1990 para alcançar um superávit de US\$ 5,4 bilhões em 2005. Apesar de serem produtos que ficaram abaixo da média de retenção calculada para os fluxos intraOCDE, eles apresentam VCRs superiores, o que pode ser um nicho para conquista de novas e maiores oportunidades na inserção externa do país.

Em linhas gerais, a matriz de dinamismo apresenta uma fotografia ampla da situação da "competitividade" externa vista por meio do comércio, de forma que seja possível distinguir nichos e suas peculiaridades. Com o propósito de complementar a análise anterior do caso brasileiro, apresenta-se, na sequência, um exame sucinto das matrizes de dinamismo elaboradas para cada uma das dez categorias tecnológicas discutidas por Lall (2000), ou seja, para cada uma das 10 categorias foi construída uma matriz, detalhada à frente. Isso possibilita melhor entendimento do dinamismo comercial, pois propicia uma visão desagregada das estatísticas sob a perspectiva tecnológica.

\section{a. Categorias que formam o grupo Produtos Básicos}

1. Produtos Primários - Primeira categoria mostrar resultados interessantes, sobretudo, no que se refere ao primeiro quadrante. Nesse filtro, só apareceu um grupo de produtos - alumínio - o único a apresentar superávit comercial perante os outros três quadrantes, com exportações e valores médios relativamente altos. Nos demais quadrantes, prevaleceram os déficits, no entanto, com taxas de crescimento das exportações bastante elevadas. Mesmo sendo uma categoria com grande destaque na pauta de exportações brasileiras, o filtro estabelecido indica que o crescimento das vendas contempla mais os quadrantes com VCRs inferiores à unidade.

2. Produtos agroflorestais (BR1) - É uma categoria cujos produtos foram marcados por superávits comerciais e taxas de crescimento das exportações elevadas entre 1995 e 2005, com destaque para o primeiro e terceiro quadrantes. Os itens com VCR superior a 1 foram aqueles que responderam pelos maiores montantes de exportação. Os maiores valores médios, no entanto, estiveram concentrados no quadrante menos dinâmico (VCR inferior a 1 e abaixo da média da retenção da OCDE). O fato de as exportações estarem concentradas nos 
produtos com VCR superiores a 1 indica que a venda desses itens agroflorestais mantém-se concentrada nos de maior competitividade internacional.

3. Outros produtos baseados em recursos (BR2) - Aqui se verifica uma extensão das características da categoria anterior. Os superávits estão presentes em todos os quadrantes com exceção do terceiro que deteve exportações relativamente menores. Ele, contudo, responde pelos maiores valores médios, em contraposição ao primeiro quadrante, fato contrário ao desejado. De maneira geral, nota-se que menos da metade dos grupos de produtos na categoria tem obtido uma inserção diferenciada, sobretudo àqueles com VCR superior à unidade.

\section{b. Categorias que formam o grupo Baixa Tecnologia}

4. Têxtil/Vestuário/Calçados (BT1) - No primeiro quadrante da categoria, o principal em termos de dinamismo, não foram verificados fluxos comerciais. $\mathrm{O}$ destaque no que se refere ao volume de comércio coube ao segundo quadrante que detém produtos com VCR inferior a 1. Seus valores médios foram elevados, mas inferiores ao terceiro quadrante, marcado por déficits e pelo maior número de grupos de produtos. Os produtos do terceiro e quarto quadrantes responderam por mais de $90 \%$ das exportações da categoria.

5. Outros produtos de baixa tecnologia (BT2) - É uma categoria tecnológica que respondeu por uma dispersão maior dos fluxos de exportação entre os quatro quadrantes. As taxas de crescimento foram bastante elevadas, sobretudo entre 1995 e 2005. O primeiro quadrante foi, todavia, aquele que deteve a menor taxa de crescimento, mas respondeu por superávits em todos os anos observados. Ademais, seus valores médios foram superiores aos dos outros produtos que detiveram VCR superior à unidade, mas inferiores aos demais quadrantes. Chamou a atenção o resultado dos valores médios do terceiro quadrante, não só por terem sido os maiores registrados, mas também por seus déficits a partir de 1995.

\section{c. Categorias que formam o grupo Média Tecnologia}

6. Automotivos (MT1) - Nesse grupo de produtos, só houve registro de transações comerciais no segundo quadrante (VCR inferior à unidade e acima da média do Índice de Retenção da OCDE). Em 2005, as exportações dos itens selecionados para o caso chegaram a quase 10 bilhões de dólares. Somente com exceção de 1995, que marcou déficits devido ao programa de estabilização com âncora cambial e às alíquotas que incentivaram o consumo exagerado de importados, em todos os demais anos apresentados houve superávit. Assim, mesmo não possuindo VCR alta, trata-se de produtos que têm acompanhado o perfil da demanda internacional. 
7. Processos (MT2) - $\mathrm{O}$ primeiro e segundo quadrantes referentes às mercadorias das indústrias de processo responderam por $85 \%$ dos fluxos de exportação em 2005 , enquanto no quarto quadrante, não houve registro de produto algum. O comportamento, no entanto, dentre os dois grupos de produtos acima da média de retenção calculada para os países da OCDE foi distinto devido ao fato de que não houve déficits no primeiro quadrante, enquanto no segundo, isso ocorreu ao longo de todos os anos. Assim, demonstra ser um segmento em que se aproveitam os diferenciais em termos de VCR, apesar de seus valores médios ainda inferiores aos possuídos pelos itens com VCR menores.

8. Engenharia (MT3) - Mais uma vez, o primeiro e segundo quadrantes responderam por ampla maioria das transações e, da mesma forma, os dois casos diferenciaram-se em termos do déficit, registrados para os itens com VCR inferior à unidade e acima da média de retenção da OCDE. O terceiro quadrante também foi marcado por déficits em todos os anos, mas respondeu por valores médios elevados, ainda que não superiores aos vistos para os produtos do quarto quadrante o qual compreendeu somente um grupo de mercadorias (estações de rádio-base). Apesar de este quadrante conter um grupo de produtos de conteúdo tecnológico mais evidente e valores médios altos, suas exportações foram pequenas relativamente aos demais casos e decrescente com o passar dos anos.

\section{d. Categorias que formam o grupo Alta Tecnologia}

9. Eletrônicos/Elétricos (AT1) - Categoria em que só houve fluxos de exportações para grupos de mercadorias com VCR inferiores à unidade. Isso deixa muito claro que o país não é internacionalmente competitivo no ramo, ao menos no que se refere aos nichos mais dinâmicos. Outra constatação é que, no terceiro e segundo quadrantes, as vendas foram inferiores às compras, gerando déficits em todos os anos examinados. Ademais, trata-se de produtos com valor médio elevado, com destaque para os casos em que a VCR é inferior à unidade e estão abaixo da média de retenção calculada para a $\mathrm{OCDE}$, ou seja, a situação não tem sido propícia "dinamicamente" para a inserção internacional desses itens.

10. Outros produtos de alta tecnologia (AT2) - A diferença da categoria para a anterior é que o filtro de seleção separou somente um único grupo de produtos (produtos químicos inorgânicos à base de metais preciosos) com VCR superior a 1 (quarto quadrante) e, ainda, superavitário. Seus valores médios, todavia, foram bastante inferiores aos verificados no segundo quadrante, o qual contemplou a maior parcela das exportações e déficits recorrentes. Apesar da exceção do único grupo de produtos a deter VCR maior que a unidade, na categoria tecnológica AT2 também não foi possível encontrar produtos mais dinâmicos a partir do critério de seleção utilizado (ou seja, não houve fluxos no primeiro quadrante). 


\section{Considerações finais}

A evolução da estrutura comercial brasileira avaliada sob a perspectiva de sua intensidade tecnológica e do dinamismo da demanda externa vem-se tornando, ao longo do tempo, cada vez mais importante no debate sobre as perspectivas de crescimento do país. É indiscutível o crescente processo de integração econômica mundial, de forma que alcançar uma inserção mais nobre no comércio é uma condição necessária para sustentar o crescimento com equilíbrio externo.

Neste trabalho, considera-se o comércio exterior de um país uma ferramenta de suma importância para a obtenção de informações relevantes sobre o perfil da estrutura produtiva interna. A capacidade de um país de concorrer em setores mais intensivos em tecnologia (refletida na estrutura de suas exportações) tem sido utilizada como espécie de "termômetro" das capacidades tecnológicas internas, na medida em que o mercado externo é o grande teste (do ponto de vista dos resultados) das referidas capacidades.

Com esse objetivo, procurou-se um indicador que levara em conta o dinamismo tecnológico e de demanda das exportações. Por um lado, foi comparada a estrutura das exportações brasileiras com a do comércio intraOCDE, captada por meio do Índice de Retenção. Admite-se, implicitamente, que o padrão de comércio intraOCDE tem níveis de dinamismo tecnológico e de demanda superiores ao resto do mundo (por serem países na fronteira tecnológica), portanto representa um bom benchmark com o qual se pode contrastar o desempenho do Brasil. Tal indicador foi complementado pela classificação de setores segundo intensidade tecnológica proposta por Lall (2000). A ideia é que a combinação de ambos os índices gerariam uma proxy adequada para examinar o dinamismo exportador brasileiro.

Ao mesmo tempo, a especialização produtiva foi mensurada por um indicador convencional, o Índice de Vantagem Comparativa Revelada (VCR). Cruzando as informações proporcionadas pelo Índice de Retenção, a tipologia de Lall (2000) e o VCR, foi possível obter uma matriz do dinamismo das exportações brasileiras.

Os resultados mostram que os itens Baseados em Recursos e Média Tecnologia dominaram as maiores parcelas das exportações presentes nos quadrantes da matriz em que o índice de retenção estava acima da média e a VCR superior era superior à unidade, sem que se registrasse, nesse caso, bens de Alta Tecnologia. Nos quadrantes em que ocorreu a condição oposta, ou seja, VCR inferior a 1, verificou-se que as mercadorias classificadas como de Alta Tecnologia responderam por participações relativas maiores. É importante notar que, embora se confirme setores de alta tecnologia não destacados no padrão de 
especialização do Brasil, existem vários itens com Índice de Retenção acima da média com peso importante e crescente nas exportações.

A matriz de dinamismo construída neste artigo representa, de forma sintética, um panorama sobre os segmentos em que o país detém competitividade externa sob o ponto de vista da demanda internacional (além disso, da importância produtiva-tecnológica) e do índice de vantagem comparativa revelada. Um ponto fundamental a destacar-se é que o Brasil tem apresentado um potencial muito importante no que se refere à diversificação e ao avanço na direção de setores dinâmicos (não só pelo lado da demanda, mas da incorporação tecnológica). Isso tem sido puxado por sua base industrial ampla e presença em diversos segmentos mais intensivos em tecnologia. A ausência, porém, de um marco claro e objetivo de instituições e políticas favoráveis ao aprendizado (relacionadas à pesquisa e desenvolvimento e propulsão de capital humano adequado) e às exportações tem impedido explorar mais efetivamente tamanho potencial, sobretudo quando comparado, por exemplo, com alguns países asiáticos.

\section{Referências bibliográficas}

AMABLE, B.; VERSPAGEN, B. The role of technology in markets shares dynamics. Applied Economics, v. 27, p. 197-224, 1995.

ANDERSSON, M.; EJERMO, O. Technology and trade: an analysis of technology specialization and export flows. Royal Institute of Technology. Centre of Excellence for Science and Innovation Studies - CESIS, 2006. (Electronic Working Paper Series, n. 65).

BALASSA, B. Trade liberalization and 'revealed' comparative advantage. The Manchester School of Economic and Social Studies, n. 33, 1965.

BARROS, J. R. M. de; GOLDENSTEIN, L. Reestruturação industrial: três anos de debate. In: VELLOSO, J. P. R. Brasil: desafios de um país em transformação. Rio de Janeiro: Ed. José Olympio, 1997.

BIELCHOWSKY, R. Investimento na indústria brasileira depois da abertura e do Real: o miniciclo de modernizações, 1995-97. Brasília: Cepal, 1998. 72p. Mimeografado.

CASTRO, A. B. A capacidade de crescer como problema. In: VELlOSO, J. P. R. $O$ Real, o crescimento e as reformas. Rio de Janeiro: Ed. José Olympio, 1996.

COUTINHO, L. G. A especialização regressiva: um balanço do desempenho industrial pós-estabilização. In: Brasil: desafios de um país em transformação. Rio de Janeiro: Ed. José Olympio, 1997.

DOSI, G.; PAVITT, K.; SOETE, L. Technology and trade: an overview of the literature. In: DOSI, G. et al. (Org.). The economics of technical change and international trade. Hertforshire: Harvester Wheatsheaf, 1990. 
FAGERBERG, J. International competitiveness. The Economic Journal, v. 98, n. 391, p. 335-374, 1988a.

. Why growth rates differ. In: DOSI, G.; FREEMAN, C.; NELSON, R.; SILVERBERG, G.; SOETE, L. Technical change and economic theory. London: Pinter Publishers, 1988b.

FERRAZ, J.; KUPFER, D.; HAGUENAUER, L. Competitividade, padrões de concorrência e fatores determinantes. In: FERRAZ, J. et al. (Org). Made in Brazil: desafios competitivos para a indústria. Rio de Janeiro: Campus, 1997.

FREEMAN, C. Technological infrastructure and international competitiveness. Industrial and Corporate Change, v. 13, n. 3, p. 541-569, 2004.

FURTADO, J. et al. Balanço de pagamentos tecnológico e propriedade intelectual. In: LANDI, F. R. (Coord. Geral). Indicadores de Ciência e Tecnologia e Inovação 2001/Fapesp. São Paulo: Fapesp, 2002.

GOMES, R.; RODRIGUES, H.; CARVALHO, E. G. Balanço de pagamentos tecnológico: o perfil do comércio externo de produtos e serviços com conteúdo tecnológico. In: LANDI, F. R. (Coord. Geral). Indicadores de Ciência e Tecnologia e Inovação 2004/Fapesp. São Paulo: Fapesp, 2005. cap 7.

HAUSMANN, R.; RODRIK, D.; HWANG, J. It is not much but what you export that matters. NBER Working Paper 11905. December, 2005.

LALL, S. The technological structure and performance of developing country manufactured exports, 1985-1998. Queen Elizabeth House, Jun. 2000. (QEH Working Paper, n. 44).

; WEISS, J.; ZHANG, J. The "sophistication" of exports: a new measure of product characteristics. Queen Elizabeth House, Jan. 2005. (QEH Working Papers Series, n. 123).

LAPLANE, M.; SARTI, F. Investimento Direto Estrangeiro e a retomada do crescimento sustentado nos anos 90. Economia e Sociedade, Campinas, n. 8, p. 143-181, jun. 1997.

MANDENG, O. S. Competitividad internacional y especialización. Revista de la Cepal, Santiago, n. 45, 1991.

MANI, S. Exports of high technology products from developing countries: is it real or a statistical artifact. Maastricht, Netherlands: The United Nations University. Institute for New Technologies (INTEC), 2000. (Discussion Paper Series).

MOREIRA, M. M., Estrangeiros em uma economia aberta: impactos recentes sobre produtividade, concentração e comércio exterior. BNDES/DEPEC, mar. 1999. (Texto para Discussão, n. 67).

NEGRI, F. Inovação tecnológica e exportações das firmas brasileiras. In: ENCONTRO NACIONAL DE ECONOMIA, Natal, Anpec, 2005. Anais... 
NEGRI, J. A.; FREITAS, F. Inovação tecnológica, eficiência de escala e exportações brasileiras. Brasília: Ipea, 2004. (Texto para discussão, n. 1044).

PEREIRA, W. As classificações padrões nacionais e internacionais utilizadas na apresentação dos fluxos comerciais e das estatísticas de produção industrial: importância, conexões e os problemas decorrentes. Grupo de Estudos em Economia Industrial (GEEIN), 2005. (Série Notas Metodológicas). Disponível em: http://geein.fclar.unesp.br/. Acesso em: 10 abr. 2007.

- Tecnologia e comércio internacional: exame das transações comerciais do Brasil sob a perspectiva tecnológica. Dissertação (Mestrado)-Universidade Federal do Paraná, Curitiba, 2007.

POSNER, M. V. International trade and technical change. Oxford Economic Papers, New Series, v. 13, n. 3, p. 323-341, 1961. 


\section{Anexos}

O trabalho de Lall (2000) classifica as categorias de produtos em grupos tecnológicos a partir da Standard International Trade Classification (SITC) em três dígitos (Rev. 3). O autor reagrupou todos os grupos de produtos a três dígitos nas categorias Produtos Primários, Produtos Industrializados e Outras Transações. No caso da segunda categoria, ela se divide em outras quatro - Produtos Baseados em Recursos, Baixa Tecnologia, Média Tecnologia e Alta Tecnologia. As categorias relacionadas aos produtos industrializados estão explicitadas abaixo.

Classificação Industrial por Níveis Tecnológicos

\begin{tabular}{|c|c|}
\hline Classificação & Exemplos \\
\hline Produtos Primários & $\begin{array}{l}\text { Frutas frescas, carne, arroz, cacau, chás, madeira, carvão, } \\
\text { petróleo cru, gás }\end{array}$ \\
\hline \multicolumn{2}{|l|}{ Produtos Industrializados } \\
\hline \multicolumn{2}{|l|}{ Baseados em Recursos } \\
\hline Produtos de base agroflorestal & $\begin{array}{l}\text { Frutas e carnes preparadas, bebidas, produtos de madeira, óleos } \\
\text { vegetais }\end{array}$ \\
\hline $\begin{array}{l}\text { Produtos baseados em outros } \\
\text { recursos }\end{array}$ & $\begin{array}{l}\text { Minérios concentrados, produtos de petróleo e borracha, } \\
\text { cimentos, vidros, pedras trabalhadas }\end{array}$ \\
\hline \multicolumn{2}{|l|}{ Baixa Tecnologia } \\
\hline Têxteis & $\begin{array}{l}\text { Tecidos, vestuário, toucas, produtos de couro, materiais de } \\
\text { viagem }\end{array}$ \\
\hline $\begin{array}{l}\text { Outros itens de baixa } \\
\text { tecnologia }\end{array}$ & $\begin{array}{l}\text { Cerâmicas, partes/estruturas de metal simples, móveis, jóias, } \\
\text { brinquedos, produtos plásticos }\end{array}$ \\
\hline \multicolumn{2}{|l|}{ Média Tecnologia } \\
\hline Produtos automotivos & $\begin{array}{l}\text { Partes e veículos de passageiros, veículos comerciais, } \\
\text { motocicletas }\end{array}$ \\
\hline Indústrias de processo & $\begin{array}{l}\text { Fibras sintéticas, tintas/cosméticos, fertilizantes, plásticos, ferro, } \\
\text { tubos }\end{array}$ \\
\hline Indústrias de engenharia & $\begin{array}{l}\text { Máquinas, motores, maquinaria industrial, bombas (ar, gasolina } \\
\text { etc.), engrenagens de câmbio, barcos, relógios }\end{array}$ \\
\hline \multicolumn{2}{|l|}{ Alta Tecnologia } \\
\hline Produtos eletrônicos e elétricos & $\begin{array}{l}\text { Equipamentos de telecomunicações, processamento e escritório, } \\
\text { televisores, transistores, turbinas, geradores }\end{array}$ \\
\hline Outros itens de alta tecnologia & $\begin{array}{l}\text { Produtos farmacêuticos, aeronaves, instrumentos de medida e } \\
\text { ópticos, câmeras }\end{array}$ \\
\hline Outras transações & $\begin{array}{l}\text { Eletricidade, filmes de cinema, classificados como transações } \\
\text { especiais, ouro, objetos de arte, moedas }\end{array}$ \\
\hline
\end{tabular}

Fonte: Lall (2000, p. 7). 
Baseados em Recursos (BR): tendem a ser intensivos em trabalho, mas há segmentos que usam tecnologias intensivas em capital, escala e conhecimentos (refino de petróleo e alimentos processados). Divisão: RB1 - produtos agro-florestais; RB2 - baseados em outros recursos.

Baixa tecnologia (BT): muitos dos produtos não têm grandes diferenciações e concorrem em preço, dado que os custos do trabalho tendem a ser elemento importante na competitividade. Economias de escala e barreiras à entrada são baixas. Divisão: LT1 têxteis, vestuários, calçados; LT2 - outros produtos de baixa tecnologia.

Média Tecnologia (MT): compreende produtos que abarcam tecnologias intensivas em escala e habilidades, nos bens de capital e produtos intermediários - trata do coração das atividades industriais de economias industriais maduras. Divisão: MT1: produtos automotivos (de interesse particular para algumas economias da América Latina e Leste da Ásia); MT2 - indústrias de processo: química e metais básicos; MT3 - produtos de engenharia.

Alta tecnologia (AT): produtos que incorporam tecnologias avançadas e rápida mudança, com altos investimentos em P\&D, enfatizando design dos produtos. Alguns produtos eletrônicos têm suas fases finais de montagem intensivas em trabalho, o que faz com que sejam realizadas em locais em que o custo do trabalho é menor. Divisão: HT1 - eletrônicos e produtos elétricos; HT2 - outros produtos de alta tecnologia: alguns equipamentos; aeronaves; instrumentos de precisão e farmacêutica.

\section{Alocação dos grupos de produtos (SITC 3) entre as categorias tecnológicas}

Produtos com crescimento das importações da OCDE positivo (1997-2001) e acima da média (63\%)

\begin{tabular}{|c|c|c|c|}
\hline \\
\hline Código & Categoria SITC (REV3) & $\begin{array}{c}\text { Categoria } \\
\text { Tecnológica (S. Lall) }\end{array}$ & $\mathrm{VCR}>1$ \\
\hline 12 & MEAT NES \& EDIBLE OFFAL, FRSH, CHLD, FRZ & RB Agro-Based & $*$ \\
\hline 16 & $\begin{array}{l}\text { MEAT, EDIBLE OFFAL, SALTED, DRIED, SMK, } \\
\text { FLOUR, ETC }\end{array}$ & RB Agro-Based & \\
\hline 17 & $\begin{array}{l}\text { MEAT \& EDBL MEAT OFFAL PREPARED OR } \\
\text { PRESRVED N.E.S. }\end{array}$ & RB Others & * \\
\hline 22 & $\begin{array}{l}\text { MILK, CREAM, MILK PRODUCTS EXCEPT } \\
\text { BUTTER OR CHEESE }\end{array}$ & Product Primary & \\
\hline 24 & CHEESE AND CURD & RB Agro-Based & \\
\hline 46 & $\begin{array}{l}\text { MEAL AND FLOUR OF WHEAT AND FLOUR OF } \\
\text { MESLIN }\end{array}$ & RB Agro-Based & \\
\hline 48 & $\begin{array}{l}\text { CERL PREPS \& PREPS OF FLR OR STRCH OF } \\
\text { FRTS OR VEGS }\end{array}$ & RB Agro-Based & \\
\hline 54 & $\begin{array}{l}\text { VEGS FR, CHLD, FROZ; ROOTS, TUBERS ETC } \\
\text { FRESH, DRIE }\end{array}$ & Product Primary & \\
\hline 56 & $\begin{array}{l}\text { VEGS, ROOTS AND TUBERS, PREPARED OR } \\
\text { PRESERVED, NES }\end{array}$ & RB Agro-Based & \\
\hline
\end{tabular}

Continua... 


\begin{tabular}{|c|c|c|c|}
\hline \multicolumn{4}{|c|}{ Continuação } \\
\hline Código & Categoria SITC (REV3) & $\begin{array}{c}\text { Categoria } \\
\text { Tecnológica (S. Lall) }\end{array}$ & $\mathrm{VCR}>1$ \\
\hline 62 & SUGAR CONFECTIONERY & RB Agro-Based & $*$ \\
\hline 73 & $\begin{array}{l}\text { CHOCOLATE \& OTHER FOOD PREPARATIONS } \\
\text { CNTG COCOA NES }\end{array}$ & RB Agro-Based & \\
\hline 91 & MARGARINE AND SHORTENING & Product Primary & \\
\hline 98 & $\begin{array}{l}\text { EDIBLE PRODUCTS AND PREPARATIONS, } \\
\text { N.E.S. }\end{array}$ & RB Agro-Based & $*$ \\
\hline 111 & NONALCOHOLIC BEVERAGES, N.E.S. & RB Agro-Based & \\
\hline 112 & ALCOHOLIC BEVERAGES & RB Agro-Based & \\
\hline 122 & $\begin{array}{l}\text { TOBACCO, MFG WHETHER CONTAINING } \\
\text { TOBACCO SUBSTITUTE }\end{array}$ & RB Agro-Based & \\
\hline 232 & $\begin{array}{l}\text { SYN RUBBER, RECLM RUB; WASTE ETC OF } \\
\text { UNHD RUBBER }\end{array}$ & RB Agro-Based & $*$ \\
\hline 335 & $\begin{array}{l}\text { RESIDUAL PETROLEUM PRODUCTS, N.E.S. } \\
\text { ETC }\end{array}$ & RB Others & \\
\hline 351 & ELECTRIC CURRENT & LT2 Others Products & \\
\hline 511 & $\begin{array}{l}\text { HYDROCARBONS NES \& SPECIFIED } \\
\text { DERIVATIVES }\end{array}$ & RB Others & \\
\hline 516 & ORGANIC CHEMICALS, N.E.S. & RB Others & $*$ \\
\hline 533 & $\begin{array}{l}\text { PIGMENTS, PAINTS, VARNISHES AND } \\
\text { RELATED MATERIALS }\end{array}$ & MT2 Process & \\
\hline 541 & $\begin{array}{l}\text { MEDICINAL ETC PRODUCTS, EXCEPT } \\
\text { MEDICAMENTS }\end{array}$ & HT2 Others & \\
\hline 542 & $\begin{array}{l}\text { MEDICAMENTS (INCLUDING VETERINARY } \\
\text { MEDICAMENTS) }\end{array}$ & HT2 Others & \\
\hline 551 & $\begin{array}{l}\text { ESSENTIAL OILS, PERFUME AND FLAVOR } \\
\text { MATERIALS }\end{array}$ & RB Others & \\
\hline 553 & $\begin{array}{l}\text { PERFUMERY, COSMETICS OR TOILET PREP, } \\
\text { EXCEPT SOAPS }\end{array}$ & MT2 Process & \\
\hline 554 & $\begin{array}{l}\text { SOAP, CLEANSING AND POLISHING } \\
\text { PREPARATIONS }\end{array}$ & MT2 Process & \\
\hline 571 & $\begin{array}{l}\text { POLYMERS OF ETHYLENE, IN PRIMARY } \\
\text { FORMS }\end{array}$ & MT2 Process & $*$ \\
\hline 572 & POLYMERS OF STYRENE, IN PRIMARY FORMS & MT2 Process & \\
\hline 574 & $\begin{array}{l}\text { POLYACETALS ETC, EPOXIDE RESINS ETC, } \\
\text { PRIMARY FORMS }\end{array}$ & MT2 Process & \\
\hline 575 & PLASTICS, N.E.S., IN PRIMARY FORMS & MT2 Process & \\
\hline 581 & TUBES, PIPES AND HOSES OF PLASTICS & MT2 Process & \\
\hline 582 & $\begin{array}{l}\text { PLATES, SHEETS, FILM, FOIL \& STRIP OF } \\
\text { PLASTICS }\end{array}$ & MT2 Process & \\
\hline 583 & $\begin{array}{l}\text { MONOFIL, CR-SECT OV } 1 \text { MM, RODS ETC, OF } \\
\text { PLASTICS }\end{array}$ & MT2 Process & \\
\hline
\end{tabular}

Continua... 


\begin{tabular}{|c|c|c|c|}
\hline \multicolumn{4}{|c|}{ Continuação } \\
\hline Código & Categoria SITC (REV3) & $\begin{array}{c}\text { Categoria } \\
\text { Tecnológica (S. Lall) }\end{array}$ & $\mathrm{VCR}>1$ \\
\hline 592 & $\begin{array}{l}\text { STARCHES, INULIN \& WH GLUTEN; ALBUMIN } \\
\text { SUBST; GLUES }\end{array}$ & RB Others & $*$ \\
\hline 598 & $\begin{array}{l}\text { MISCELLANEOUS CHEMICAL PRODUCTS, } \\
\text { N.E.S. }\end{array}$ & MT2 Process & \\
\hline 621 & $\begin{array}{l}\text { MATERIALS OF RUBBER (PASTES, PLATES, } \\
\text { SHEETS, ETC.) }\end{array}$ & RB Agro-Based & \\
\hline 625 & $\begin{array}{l}\text { RUBBER TIRES, INTER TREADS, TIRE FLAPS \& } \\
\text { INN TUBES }\end{array}$ & RB Agro-Based & $*$ \\
\hline 629 & ARTICLES OF RUBBER, N.E.S. & RB Agro-Based & \\
\hline 641 & PAPER AND PAPERBOARD & RB Agro-Based & \\
\hline 642 & $\begin{array}{l}\text { PAPER \& PAPERBOARD, CUT TO SIZE OR } \\
\text { SHAPE, ARTICLES }\end{array}$ & LT2 Others Products & $*$ \\
\hline 656 & $\begin{array}{l}\text { TULLES, LACE, EMBROIDERY, RIBBONS, } \\
\text { TRIMMINGS, ETC. }\end{array}$ & $\begin{array}{l}\text { LT1 Textile, } \\
\text { Garment and } \\
\text { Footwear }\end{array}$ & \\
\hline 657 & $\begin{array}{l}\text { SPECIAL YARNS, SPECIAL TEXTILE FABRICS, } \\
\text { ETC. }\end{array}$ & $\begin{array}{l}\text { LT1 Textile, } \\
\text { Garment and } \\
\text { Footwear }\end{array}$ & \\
\hline 663 & MINERAL MANUFACTURES, N.E.S. & RB Others & \\
\hline 664 & GLASS & RB Others & \\
\hline 665 & GLASSWARE & LT2 Others Products & \\
\hline 674 & $\begin{array}{l}\text { IRON \& NA STEEL FLAT-ROLLED PRODUCTS, } \\
\text { CLAD, ETC. }\end{array}$ & LT2 Others Products & \\
\hline 676 & $\begin{array}{l}\text { IRON \& STEEL BARS, RODS, ANGLES, SHAPES } \\
\& \text { SECTIONS }\end{array}$ & LT2 Others Products & $*$ \\
\hline 679 & $\begin{array}{l}\text { IRON \& STEEL TUBES, PIPES \& HOL PROFILES, } \\
\text { FITTINGS }\end{array}$ & LT2 Others Products & $*$ \\
\hline 684 & ALUMINUM & Product Primary & $*$ \\
\hline 691 & $\begin{array}{l}\text { METAL STRUCTURES \& PARTS NES IRON, } \\
\text { STEEL, ALUMINUM }\end{array}$ & LT2 Others Products & \\
\hline 692 & $\begin{array}{l}\text { METAL CONTAINERS FOR STORAGE OR } \\
\text { TRANSPORT }\end{array}$ & LT2 Others Products & \\
\hline 695 & $\begin{array}{l}\text { TOOLS FOR USE IN THE HAND OR IN } \\
\text { MACHINES }\end{array}$ & LT2 Others Products & \\
\hline 699 & MANUFACTURES OF BASE METAL, N.E.S. & LT2 Others Products & \\
\hline 711 & $\begin{array}{l}\text { STEAM OR OTH VAPOR GENERATING } \\
\text { BOILERS, ETC }\end{array}$ & MT3 Engeneering & \\
\hline 712 & $\begin{array}{l}\text { STEAM TURBINES \& OTH VAPOR TURBINES, } \\
\text { \& PTS THEREOF }\end{array}$ & HT2 Others & \\
\hline 713 & $\begin{array}{l}\text { INTERNAL COMBUST PISTON ENGS, AND PTS, } \\
\text { N.E.S. }\end{array}$ & MT3 Engeneering & $*$ \\
\hline
\end{tabular}

Continua... 


\begin{tabular}{|c|c|c|c|}
\hline \multicolumn{4}{|c|}{ Continuação } \\
\hline Código & Categoria SITC (REV3) & $\begin{array}{c}\text { Categoria } \\
\text { Tecnológica (S. Lall) }\end{array}$ & $\mathrm{VCR}>1$ \\
\hline 714 & ENGS AND MOTORS, NONELECT \& PTS, N.E.S. & MT3 Engeneering & \\
\hline 716 & $\begin{array}{l}\text { ROTATING ELECTRIC PLANT AND PARTS } \\
\text { THEREOF, N.E.S. }\end{array}$ & $\begin{array}{l}\text { HT1 Eletronic and } \\
\text { Electrical }\end{array}$ & \\
\hline 718 & $\begin{array}{l}\text { POWER GENERATING MACHINERY \& PARTS, } \\
\text { N.E.S. }\end{array}$ & $\begin{array}{l}\text { HT1 Eletronic and } \\
\text { Electrical }\end{array}$ & \\
\hline 723 & $\begin{array}{l}\text { CIVIL ENGINEERING \& CONTRACTORS' } \\
\text { PLANT \& EQUIPMENT }\end{array}$ & MT3 Engeneering & \\
\hline 731 & $\begin{array}{l}\text { MACH TOOLS WORKNG BY REMOVING METL } \\
\text { OR OTH MATERIAL }\end{array}$ & MT3 Engeneering & \\
\hline 735 & $\begin{array}{l}\text { PARTS, N.E.S. \& ACCESS FOR MET WORK } \\
\text { MACHINE TOOLS }\end{array}$ & MT3 Engeneering & \\
\hline 741 & $\begin{array}{l}\text { HEATNG \& COOLNG EQUIPMNT AND PTS } \\
\text { THEREOF, N.E.S. }\end{array}$ & MT3 Engeneering & \\
\hline 742 & $\begin{array}{l}\text { PUMPS FOR LIQUIDS; LIQUID ELEVATORS \& } \\
\text { PTS }\end{array}$ & MT3 Engeneering & \\
\hline 743 & $\begin{array}{l}\text { PUMPS, AIR OR OTHER GAS COMPRESSORS } \\
\text { AND FANS }\end{array}$ & MT3 Engeneering & $*$ \\
\hline 744 & $\begin{array}{l}\text { MECHANICAL HANDLNG EQUIPMT, \& PTS } \\
\text { THEREOF, N.E.S. }\end{array}$ & MT3 Engeneering & \\
\hline 745 & $\begin{array}{l}\text { NONELECTRICAL MACHRY, TOOLS, APP \& } \\
\text { PTS, N.E.S. }\end{array}$ & MT3 Engeneering & \\
\hline 747 & TAPS, COCKS, VALVES \& SIM APPLIANCES & MT3 Engeneering & \\
\hline 748 & $\begin{array}{l}\text { TRASMISSION SHAFTS AND CRANKS; } \\
\text { BEARNG HOUSNGS, ETC }\end{array}$ & MT3 Engeneering & $*$ \\
\hline 749 & $\begin{array}{l}\text { NONELECTRIC PARTS \& ACCESSORIES OF } \\
\text { MACHRY NES }\end{array}$ & MT3 Engeneering & \\
\hline 761 & TELEVISION RECEIVERS & $\begin{array}{l}\text { HT1 Eletronic and } \\
\text { Electrical }\end{array}$ & \\
\hline 764 & $\begin{array}{l}\text { TELECOMMUNICATIONS EQUIPMENT, N.E.S. } \\
\text { \& PTS, N.E.S. }\end{array}$ & $\begin{array}{l}\text { HT1 Eletronic and } \\
\text { Electrical }\end{array}$ & \\
\hline 772 & $\begin{array}{l}\text { ELECRICL APPARAT FOR SWITCHG OR } \\
\text { PROTECTG ELEC CIRC }\end{array}$ & MT3 Engeneering & \\
\hline 773 & $\begin{array}{l}\text { EQUIPMENT FOR DISTRIBUTING } \\
\text { ELECTRICITY, N.E.S. }\end{array}$ & MT3 Engeneering & \\
\hline 774 & ELECTRO-DIAGNOSTIC APPARATUS & $\begin{array}{l}\text { HT1 Eletronic and } \\
\text { Electrical }\end{array}$ & \\
\hline 775 & $\begin{array}{l}\text { HOUSEHLD TYPE ELEC \& NONELEC } \\
\text { EQUIPMENT, N.E.S. }\end{array}$ & MT3 Engeneering & \\
\hline 778 & $\begin{array}{l}\text { ELECTRICAL MACHINERY AND APPARATUS, } \\
\text { N.E.S. }\end{array}$ & $\begin{array}{l}\text { HT1 Eletronic and } \\
\text { Electrical }\end{array}$ & \\
\hline 781 & MOTOR CARS \& OTH MOTOR VEHICLES & MT1 Automotive & \\
\hline
\end{tabular}




\begin{tabular}{|c|c|c|c|}
\hline \multicolumn{4}{|c|}{ Continuação } \\
\hline Código & Categoria SITC (REV3) & $\begin{array}{c}\text { Categoria } \\
\text { Tecnológica (S. Lall) }\end{array}$ & $\mathrm{VCR}>1$ \\
\hline 782 & $\begin{array}{l}\text { MOTOR VEHICLES FOR TRANSPT OF GDS \& } \\
\text { SPEC PUR VEHS }\end{array}$ & MT1 Automotive & \\
\hline 784 & $\begin{array}{l}\text { PARTS AND ACCESSORIES OF MOTOR } \\
\text { VEHICLES, ETC }\end{array}$ & MT1 Automotive & \\
\hline 785 & $\begin{array}{l}\text { MOTORCYCLES AND CYCLES, MOTORIZED \& } \\
\text { NOT MOTORIZED }\end{array}$ & MT1 Automotive & \\
\hline 786 & $\begin{array}{l}\text { TRAILERS \& SEMI-TRAILRS; OTH VEH NT } \\
\text { MECHAN PROPLD }\end{array}$ & MT2 Process & \\
\hline 791 & $\begin{array}{l}\text { RAILWAY VEHICLES \& ASSOCIATED } \\
\text { EQUIPMENT }\end{array}$ & MT2 Process & \\
\hline 811 & PREFABRICATED BUILDINGS & MT3 Engeneering & \\
\hline 871 & $\begin{array}{l}\text { OPTICAL INSTRUMENTS AND APPARATUS, } \\
\text { NES }\end{array}$ & HT2 Others & \\
\hline 872 & $\begin{array}{l}\text { INST \& APPLS, NES, FOR MEDICAL, DENTAL } \\
\text { ETC PURPOSE }\end{array}$ & MT3 Engeneering & \\
\hline 873 & METERS AND COUNTERS, NES & MT3 Engeneering & \\
\hline 874 & $\begin{array}{l}\text { MEASURING/CHECKING/ANALYSING \& } \\
\text { CONTR INST\&APPT NES }\end{array}$ & HT2 Others & \\
\hline 881 & $\begin{array}{l}\text { PHOTOGRAPHIC APPARATUS AND } \\
\text { EQUIPMENT, NES }\end{array}$ & HT2 Others & \\
\hline 883 & $\begin{array}{l}\text { CINEMA FILM, EXP/DEVELOP WHET/NT } \\
\text { INCOR SOUND TRACK }\end{array}$ & MT2 Process & \\
\hline 884 & OPTICAL GOODS, NES & MT3 Engeneering & \\
\hline 892 & PRINTED MATTER & LT2 Others Products & \\
\hline 893 & ARTICLES, NES OF PLASTICS & LT2 Others Products & \\
\hline 897 & $\begin{array}{l}\text { JEWELRY, GOLDSMITHS' \& SILVERSMITHS' } \\
\text { WARES ETC }\end{array}$ & LT2 Others Products & \\
\hline 898 & $\begin{array}{l}\text { MUSICAL INSTRUMENTS AND PARTS, } \\
\text { RECORDS, TAPES ETC }\end{array}$ & LT2 Others Products & \\
\hline 931 & $\begin{array}{l}\text { SPECIAL TRANSACTIONS \& COMMOD NOT } \\
\text { CLASSIF BY KIND }\end{array}$ & LT2 Others Products & \\
\hline
\end{tabular}


Produtos com crescimento das importações da OCDE positivo (1997-2001) e abaixo da média (63\%)

\begin{tabular}{|c|c|c|c|}
\hline Código & Categoria SITC (REV3) & $\begin{array}{c}\text { Categoria } \\
\text { Tecnológica (S. Lall) }\end{array}$ & $\mathrm{VCR}>1$ \\
\hline 34 & $\begin{array}{l}\text { FISH, FRESH (LIVE OR DEAD), CHILLED OR } \\
\text { FROZEN }\end{array}$ & Product Primary & \\
\hline 36 & $\begin{array}{l}\text { CRUSTACEAN ETC FRSH, CH, FZ, DRD, } \\
\text { SALTED, ETC. }\end{array}$ & Product Primary & $*$ \\
\hline 37 & $\begin{array}{l}\text { FISH/CRUSTACEANS/MOLLUSCS/AQ INVBRTE } \\
\text { PREP/PRES NES }\end{array}$ & RB Agro-Based & \\
\hline 74 & TEA AND MATE & Product Primary & $*$ \\
\hline 75 & SPICES & Product Primary & $*$ \\
\hline 245 & $\begin{array}{l}\text { FUEL WOOD (EXCLUDING WOOD WASTE) \& } \\
\text { WOOD CHARCOAL }\end{array}$ & Product Primary & $*$ \\
\hline 251 & PULP AND WASTE PAPER & RB Agro-Based & $*$ \\
\hline 265 & $\begin{array}{l}\text { VEG TEX FIBERS; RAW OR PROC BUT NOT } \\
\text { SPUN; WASTE }\end{array}$ & RB Agro-Based & $*$ \\
\hline 289 & $\begin{array}{l}\text { ORES \& CONCEN OF PRECIOUS METAL \& } \\
\text { WASTE, SCRAP ETC }\end{array}$ & RB Others & \\
\hline 321 & $\begin{array}{l}\text { COAL, PULVERIZED OR NOT, BUT NOT } \\
\text { AGGLOMERATED }\end{array}$ & Product Primary & \\
\hline 325 & $\begin{array}{l}\text { COKE, SEMICOKE ETC OF COAL, LIGNITE ETC; } \\
\text { RE CARBON }\end{array}$ & RB Others & \\
\hline 333 & $\begin{array}{l}\text { CRUDE OIL FROM PETROLEUM OR } \\
\text { BITUMINOUS MINERALS }\end{array}$ & Product Primary & $*$ \\
\hline 334 & $\begin{array}{l}\text { OIL (NOT CRUDE) FROM PETROL \& BITUM } \\
\text { MINERALS ETC }\end{array}$ & RB Others & \\
\hline 342 & LIQUEFIED PROPANE AND BUTANE & Product Primary & \\
\hline 343 & NATURAL GAS, WHETHER OR NOT LIQUEFIED & RB Agro-Based & \\
\hline 344 & $\begin{array}{l}\text { PETROLEUM GASES \& OTHER GASEOUS } \\
\text { HYDROCARBONS NES }\end{array}$ & RB Others & \\
\hline 513 & $\begin{array}{l}\text { CARBOXYLIC ACIDS ETC HALIDES ETC \& } \\
\text { DERIVATIVES }\end{array}$ & MT2 Process & \\
\hline 515 & $\begin{array}{l}\text { ORGANO-INORGANIC \& HETEROCYCLIC } \\
\text { COMPOUNDS ETC }\end{array}$ & RB Others & \\
\hline 524 & $\begin{array}{l}\text { INORGANIC CHEMICALS NES; PRECIOUS } \\
\text { METAL COMPOUNDS }\end{array}$ & HT2 Others & $*$ \\
\hline 525 & RADIOACTIVE AND ASSOCIATED MATERIALS & RB Others & \\
\hline 562 & FERTILIZERS (EXCEPT CRUDE OF GROUP 272) & MT2 Process & \\
\hline 593 & EXPLOSIVES AND PYROTECHNIC PRODUCTS & MT2 Process & \\
\hline 611 & LEATHER & $\begin{array}{l}\text { LT1 Textile, } \\
\text { Garment and } \\
\text { Footwear }\end{array}$ & \\
\hline
\end{tabular}


Wellington Pereira / Gabriel Porcile / João Furtado

\begin{tabular}{|c|c|c|c|}
\hline \multicolumn{4}{|c|}{ Continuação } \\
\hline Código & Categoria SITC (REV3) & $\begin{array}{c}\text { Categoria } \\
\text { Tecnológica (S. Lall) }\end{array}$ & VCR $>1$ \\
\hline 612 & $\begin{array}{l}\text { MFR OF LEATHER (INC COMPOSITION) NES; } \\
\text { SADDLERY ETC }\end{array}$ & $\begin{array}{l}\text { LT1 Textile, } \\
\text { Garment and } \\
\text { Footwear }\end{array}$ & $*$ \\
\hline 633 & CORK MANUFACTURES & RB Agro-Based & \\
\hline 634 & $\begin{array}{l}\text { VENEERS, PLYWOOD, PARTICLE BD, OTH } \\
\text { WORKED WOOD NES }\end{array}$ & RB Agro-Based & $*$ \\
\hline 635 & WOOD MANUFACTURES, N.E.S. & RB Agro-Based & $*$ \\
\hline 658 & $\begin{array}{l}\text { MADE-UP ARTICLES OF TEXTILE MATERIALS, } \\
\text { N.E.S. }\end{array}$ & $\begin{array}{l}\text { LT1 Textile, } \\
\text { Garment and } \\
\text { Footwear }\end{array}$ & $*$ \\
\hline 661 & $\begin{array}{l}\text { LIME, CEMENT \& FABRICATED CONSTRUCT } \\
\text { MATERIALS NES }\end{array}$ & RB Others & $*$ \\
\hline 667 & PEARLS, PRECIOUS \& SEMIPRECIOUS STONES & RB Others & \\
\hline 681 & $\begin{array}{l}\text { SILVER, PLATINUM \& OTHER PLATINUM } \\
\text { GROUP METALS }\end{array}$ & Product Primary & \\
\hline 694 & $\begin{array}{l}\text { NAILS, SCREWS, NUTS ETC, IRON, STEEL, } \\
\text { COPP, ALUMIN }\end{array}$ & LT2 Others Products & \\
\hline 696 & CUTLERY & LT2 Others Products & $*$ \\
\hline 697 & $\begin{array}{l}\text { HOUSEHOLD EQUIPMENT OF BASE METAL, } \\
\text { N.E.S. }\end{array}$ & LT2 Others Products & $*$ \\
\hline 752 & $\begin{array}{l}\text { AUTOMATIC DATA PROCESS MACHS \& UNITS } \\
\text { THEREOF }\end{array}$ & $\begin{array}{l}\text { HT1 Eletronic and } \\
\text { Electrical }\end{array}$ & \\
\hline 759 & $\begin{array}{l}\text { PARTS ETC FOR OFFICE MACH \& AUTO DATA } \\
\text { PROCESS MACH }\end{array}$ & $\begin{array}{l}\text { HT1 Eletronic and } \\
\text { Electrical }\end{array}$ & \\
\hline 762 & $\begin{array}{l}\text { RADIO-BROADCAST RECEIVRS WHETH/NT } \\
\text { INCR SND REC ETC }\end{array}$ & MT3 Engeneering & $*$ \\
\hline 763 & $\begin{array}{l}\text { SOUND RECORDERS, TV RECORDERS, } \\
\text { RECORDING MEDIA UNR }\end{array}$ & MT3 Engeneering & \\
\hline 771 & $\begin{array}{l}\text { ELECTRIC POWER MACHINERY, AND PARTS } \\
\text { THEREOF }\end{array}$ & $\begin{array}{l}\text { HT1 Eletronic and } \\
\text { Electrical }\end{array}$ & \\
\hline 776 & $\begin{array}{l}\text { THERMIONIC, COLD CATHODE, } \\
\text { PHOTOCATHODE VALVES ETC. }\end{array}$ & $\begin{array}{l}\text { HT1 Eletronic and } \\
\text { Electrical }\end{array}$ & \\
\hline 813 & LIGHTING FIXTURES AND FITTINGS NES & MT3 Engeneering & \\
\hline 821 & $\begin{array}{l}\text { FURNITURE \& PTS; BEDDING, MATTRESSES, } \\
\text { ETC. }\end{array}$ & LT2 Others Products & \\
\hline 831 & $\begin{array}{l}\text { TRUNKS, SUITCASES, VANITY CASES, } \\
\text { BRIEFCASES, ETC }\end{array}$ & $\begin{array}{l}\text { LT1 Textile, } \\
\text { Garment and } \\
\text { Footwear }\end{array}$ & \\
\hline 841 & $\begin{array}{l}\text { MEN'S OR BOY'S COATS, JACKETS ETC, TEXT, } \\
\text { NOT KNIT }\end{array}$ & $\begin{array}{l}\text { LT1 Textile, } \\
\text { Garment and } \\
\text { Footwear }\end{array}$ & \\
\hline
\end{tabular}




\begin{tabular}{|c|c|c|c|}
\hline Código & Categoria SITC (REV3) & $\begin{array}{c}\text { Categoria } \\
\text { Tecnológica (S. Lall) }\end{array}$ & $\mathrm{VCR}>1$ \\
\hline 842 & $\begin{array}{l}\text { WOMEN/GIRLS COATS, CAPES ETC, TEX } \\
\text { FABRIC, NOT KNIT }\end{array}$ & $\begin{array}{l}\text { LT1 Textile, } \\
\text { Garment and } \\
\text { Footwear }\end{array}$ & \\
\hline 845 & $\begin{array}{l}\text { ARTICLES OF APPAREL OF TEXTILE FABRICS } \\
\text { NES }\end{array}$ & $\begin{array}{l}\text { LT1 Textile, } \\
\text { Garment and } \\
\text { Footwear }\end{array}$ & \\
\hline 848 & $\begin{array}{l}\text { APPAREL \& CL ACC EXC TEXTILE; } \\
\text { HEADGEAR, ALL MATERL }\end{array}$ & $\begin{array}{l}\text { LT1 Textile, } \\
\text { Garment and } \\
\text { Footwear }\end{array}$ & \\
\hline 851 & FOOTWEAR & $\begin{array}{l}\text { LT1 Textile, } \\
\text { Garment and } \\
\text { Footwear }\end{array}$ & $*$ \\
\hline 894 & $\begin{array}{l}\text { BABY CARRIAGES, TOYS, GAMES AND } \\
\text { SPORTING GOODS }\end{array}$ & LT2 Others Products & \\
\hline 895 & OFFICE AND STATIONERY SUPPLIES, N.E.S. & LT2 Others Products & \\
\hline 896 & $\begin{array}{l}\text { WORKS OF ART, COLLECTORS' PIECES AND } \\
\text { ANTIQUES }\end{array}$ & LT2 Others Products & \\
\hline 899 & $\begin{array}{l}\text { MISCELLANEOUS MANUFACTURED } \\
\text { ARTICLES, N.E.S. }\end{array}$ & LT2 Others Products & $*$ \\
\hline
\end{tabular}

Fonte: Secex. Elaboração própria. 